\title{
Systematic Mutagenesis of $\alpha$-Synuclein Reveals Distinct Sequence Requirements for Physiological and Pathological Activities
}

\author{
Jacqueline Burré, ${ }^{1}$ Manu Sharma, ${ }^{1}$ and Thomas C. Südhof ${ }^{1,2}$ \\ ${ }^{1}$ Department of Molecular and Cellular Physiology, Stanford University, Stanford, California 94305-5453, and 2Howard Hughes Medical Institute, Stanford \\ University, Stanford, California 94305-5453
}

$\alpha$-Synuclein is an abundant presynaptic protein that binds to phospholipids and synaptic vesicles. Physiologically, $\alpha$-synuclein functions as a SNARE-protein chaperone that promotes SNARE-complex assembly for neurotransmitter release. Pathologically, $\alpha$-synuclein mutations and $\alpha$-synuclein overexpression cause Parkinson's disease, and aggregates of $\alpha$-synuclein are found as Lewy bodies in multiple neurodegenerative disorders ("synucleinopathies"). The relation of the physiological functions to the pathological effects of $\alpha$-synuclein remains unclear. As an initial avenue of addressing this question, we here systematically examined the effect of $\alpha$-synuclein mutations on its physiological and pathological activities. We generated $26 \alpha$-synuclein mutants spanning the entire molecule, and analyzed them compared with wild-type $\alpha$-synuclein in seven assays that range from biochemical studies with purified $\alpha$-synuclein, to analyses of $\alpha$-synuclein expression in cultured neurons, to examinations of the effects of virally expressed $\alpha$-synuclein introduced into the mouse substantia nigra by stereotactic injections. We found that both the $\mathrm{N}$-terminal and $\mathrm{C}$-terminal sequences of $\alpha$-synuclein were required for its physiological function as SNARE-complex chaperone, but that these sequences were not essential for its neuropathological effects. In contrast, point mutations in the central region of $\alpha$-synuclein, referred to as nonamyloid $\beta$ component (residues 61-95), as well as point mutations linked to Parkinson's disease (A30P, E46K, and A53T) increased the neurotoxicity of $\alpha$-synuclein but did not affect its physiological function in SNARE-complex assembly. Thus, our data show that the physiological function of $\alpha$-synuclein, although protective of neurodegeneration in some contexts, is fundamentally distinct from its neuropathological effects, thereby dissociating the two activities of $\alpha$-synuclein.

\section{Introduction}

$\alpha$-Synuclein is a small abundant neuronal protein that is natively unstructured, but folds into amphipathic $\alpha$-helices in the presence of negatively charged lipids (Maroteaux et al., 1988; Perrin et al., 2000), binds to synaptobrevin-2/VAMP2 (Burré et al., 2010), and localizes to synaptic vesicles in nerve terminals (Iwai et al., 1995). In vitro and in cultured cells and neurons, $\alpha$-synuclein promotes SNARE-complex assembly (Burré et al., 2010). Three synuclein genes are expressed in mammals that encode $\alpha$-synuclein, $\beta$-synuclein, and $\gamma$-synuclein. $\alpha / \beta / \gamma$-Synuclein triple knock-out $(\mathrm{KO})$ mice develop progressive neuropathology

Received July 24, 2012; revised Aug. 20, 2012; accepted Sept. 2, 2012.

Author contributions: J.B. and T.C.S. designed research; J.B. and M.S. performed research; J.B. and M.S. analyzed data; J.B., M.S., and T.C.S. wrote the paper.

We thank Dr. Xiaofei Yang for breeding of synaptobrevin-2 KO mice, Dr. Stephan Lammel for assistance with lentiviral injections, and Christian Burré (CircumFlex Computer Systems) for help with data analysis. This work was supported by grants from the National Institute of Neurological Disorders and Stroke (NS077906 to T.C.S.) and the National Institute of Aging (AG010770 to T.C.S.), and by postdoctoral fellowships from the German Academy of Sciences Leopoldina (BMBF-LPD 9901/8-161 to J.B.), and from the Human Frontiers Program (LT00527/2006-L to M.S.).

The authors declare no competing financial interests.

Correspondence should be addressed to either of the following: Jacqueline Burré, Department of Molecular and Cellular Physiology, Stanford University, SIM1, 265 Campus Drive, Stanford, California 94305-5453, E-mail: burre@stanford.edu; or Thomas C. Südhof, Howard Hughes Medical Institute, Stanford University, SIM1, 265 Campus Drive, Stanford, California 94305, E-mail: tcs1@stanford.edu.

DOI:10.1523/JNEUROSCI.3545-12.2012

Copyright $\odot 2012$ the authors $\quad 0270-6474 / 12 / 3215227-16 \$ 15.00 / 0$ and motor impairments, die prematurely, and exhibit impaired SNARE-complex assembly, which is consistent with the idea that $\alpha$-synuclein functions as a SNARE-complex chaperone (Burré et al., 2010; Greten-Harrison et al., 2010).

Aggregates of $\alpha$-synuclein are found in age-dependent disorders called synucleinopathies, including Parkinson's disease (PD), Alzheimer's disease, multiple system atrophy, and dementia with Lewy bodies (Spillantini and Goedert, 2000; Masliah et al., 2001). Both point mutations in $\alpha$-synuclein (A30P, E46K, A53T) (Polymeropoulos et al., 1997; Krüger et al., 1998; Zarranz et al., 2004) and duplication or triplication of the $\alpha$-synuclein gene (Singleton et al., 2003; Ibáñez et al., 2004) produce PD. PD-linked $\alpha$-synuclein mutations affect $\alpha$-synuclein fibril formation in vitro (Conway et al., 1998, 2000; Narhi et al., 1999; Greenbaum et al., 2005; Fredenburg et al., 2007; Yonetani et al., 2009 ), and $\alpha$-synuclein oligomers are toxic to neurons in vivo (Kayed et al., 2003; Lindersson et al., 2004; Tsika et al., 2010; Colla et al., 2012), suggesting that a toxic gain-of-function effect of $\alpha$-synuclein may produce the neurodegeneration in PD and other synucleinopathies. At least in some instances, however, the physiological function of $\alpha$-synuclein in promoting SNAREcomplex assembly protects against neurodegeneration instead of promoting it (Chandra et al., 2005). Specifically, modest overexpression of $\alpha$-synuclein rescues the lethal neurodegeneration caused by deletion of $\operatorname{CSP} \alpha$ (cysteine string protein $\alpha$ ), a chaper- 
one for the SNARE-protein SNAP-25 (Sharma et al., 2011b). $\alpha$-Synuclein blocks neurodegeneration in $\operatorname{CSP} \alpha \mathrm{KO}$ mice by compensating for the decreased SNARE-complex assembly induced by the loss of SNAP-25 in these mice (Sharma et al., 2011a). Thus, the question arises whether $\alpha$-synuclein performs independent physiological functions and pathological actions, or whether pathology induced by $\alpha$-synuclein mutations or overexpression is related to a loss of its overall physiological function.

While the pathology caused by PD-linked $\alpha$-synuclein mutants has been extensively compared with wild-type (WT) $\alpha$-synuclein, few studies have performed systematic targeted mutagenesis experiments of $\alpha$-synuclein to compare the consequences of various mutations for the neuropathogenic effects and physiological functions of $\alpha$-synuclein. Here, we set out to fill this gap in our understanding, and to clarify whether pathology in synucleinopathies is caused by a loss or gain of function of $\alpha$-synuclein. Toward this goal, we generated mutants of all sequence regions of human $\alpha$-synuclein, and examined their properties using a variety of functional and pathological readouts. Our data suggest that the physiological function and neuropathogenic effects of $\alpha$-synuclein are mediated by molecularly distinct processes.

\section{Materials and Methods}

\section{$\alpha$-Synuclein expression vectors}

A c-myc epitope with a 4 aa linker was introduced into all expression vectors, resulting in the following N-terminal sequence: EQKLISEEDLGSGS. Introduction of stop codons or point mutations were accomplished by sitedirected mutagenesis. All myc-tagged $\alpha$-synuclein mutants were inserted into either pGEX-KG for bacterial expression [with an N-terminal tobacco etch virus (TEV) cleavage site right before the myc epitope tag, leaving an extra N-terminal glycine upon proteolytic removal of the GST moiety], pCMV5 for expression in HEK293T cells, FUW for lentiviral expression in neuronal culture, or L302 (containing an IRES-driven GFP reporter) for lentiviral expression in substantia nigra upon stereotactic injection.

\section{Mice}

Synuclein triple KO mice, synaptobrevin-2 KO mice, and WT mice maintained on C57BL/6 background were maintained and bred as described previously (Schoch et al., 2001; Burré et al., 2010; Xu et al., 2012). Mice of either sex were used for stereotactic injections or primary neuronal culture. The animal protocols used in this study, as well as the overall mouse husbandry practices, were approved by the respective institutional animal care and use committees at University of Texas Southwestern Medical Center and Stanford University.

\section{Primary mouse neuronal culture}

Mouse hippocampal neurons were cultured from newborn mice essentially as described previously (Tang et al., 2006; Maximov et al., 2007). Brain regions were dissected in ice-cold HBSS, dissociated by trypsinization $(0.05 \%$ trypsin-EDTA for $10 \mathrm{~min}$ at $37^{\circ} \mathrm{C}$ ), triturated with a siliconized pipette, and plated $(100 \mathrm{ml}$ ) onto a $12 \mathrm{~mm}$ coverslip (for immunofluorescence) or on 12-well plastic dishes, coated for at least $30 \mathrm{~min}$ with Matrigel (BD Biosciences). Plating medium (MEM, Invitrogen) supplemented with $5 \mathrm{~g} / \mathrm{L}$ glucose, $0.2 \mathrm{~g} / \mathrm{L} \mathrm{NaHCO}_{3}$ (Sigma-Aldrich), $0.1 \mathrm{~g} / \mathrm{L}$ transferrin (Calbiochem), $0.25 \mathrm{~g} / \mathrm{L}$ insulin (Sigma-Aldrich), $0.3 \mathrm{~g} / \mathrm{L}$ L-glutamine (Invitrogen), and 10\% fetal bovine serum was replaced with growth medium (MEM, Invitrogen) containing $5 \mathrm{~g} / \mathrm{L}$ glucose, $0.2 \mathrm{~g} / \mathrm{L} \mathrm{NaHCO}_{3}$ (Sigma-Aldrich), $0.1 \mathrm{~g} / \mathrm{L}$ transferrin (Calbiochem), $0.3 \mathrm{~g} / \mathrm{L}$ L-glutamine (Invitrogen), $5 \%$ fetal bovine serum, 2\% B-27 supplement (Invitrogen), and $2 \mathrm{~mm}$ cytosine arabinoside (Sigma-Aldrich) 24-48 h after plating. Cultured neurons were transduced with recombinant lentiviruses and used for experiments as indicated.

\section{Lentiviral vector production, transduction, and expression}

Lentiviral vector (FUW containing myc-tagged $\alpha$-synuclein mutants or empty vector), VSVG (vesicular stomatitis virus glycoprotein), and $\Delta 8.9$ HIV-1 packaging vectors were cotransfected in a 1:1:1 molar ratio into HEK293T cells (ATCC) in neuronal growth medium using Fugene-6 (Roche). Medium containing the viral particles was collected $48 \mathrm{~h}$ later and centrifuged for $10 \mathrm{~min}$ at $2000 \mathrm{rpm}$ to remove any cellular debris. The supernatant containing virions was added to cultured neurons at 7 DIV, and the expression of the recombinant proteins was monitored at 21 DIV.

\section{Expression of $\alpha$-synuclein mutants in substantia nigra}

Lentiviral vector L302 containing an IRES-driven GFP reporter (containing myc-tagged $\alpha$-synuclein mutants), VSVG, Rev, and RRE (Revresponsive element) were cotransfected in a 1:1:1:1 molar ratio into HEK293T cells as described above. Viral particles were concentrated by centrifugation at $50,000 \mathrm{~g}_{\text {av }}$ for $90 \mathrm{~min}$. The viral pellet was resuspended in neuronal medium (at $1 / 50$ of the precentrifugation volume) containing $4 \mathrm{mg} / \mathrm{ml}$ polybrene (Sigma-Aldrich), snap-frozen in liquid $\mathrm{N}_{2}$, and kept at $-80^{\circ} \mathrm{C}$.

CD1 mice (P40-P45, Charles River Laboratories) were anesthetized by intraperitoneal injection of $125-250 \mathrm{mg} / \mathrm{kg}$ Avertin (tribromoethanol, Sigma-Aldrich). One microliter of viral solution was delivered through a glass pipette at a flow rate of $0.15 \mu \mathrm{l} / \mathrm{min}$ unilaterally (left hemisphere) at the following coordinates: anteroposterior, $2.6-3.3 \mathrm{~mm}$ posterior to bregma (determined based on lambda-to-bregma distance of each mouse); lateral, $1 \mathrm{~mm}$ from midline suture; ventral, $4.2 \mathrm{~mm}$ below brain surface. Following $10 \mathrm{~d}$ of recovery, analysis of mouse behavior was commenced.

\section{Behavioral studies}

Beam-walking test was used to record deficits in balance and limb control (accuracy and strength in limb placement). Animal's ability to navigate across a beam to return to its home cage was tested using a wooden dowel (cylindrical beam $60 \mathrm{~cm}$ in length, $1 \mathrm{~cm}$ in diameter). The beam was steadily fixed on both ends $40 \mathrm{~cm}$ above the ground leading to a small cage filled with bedding from the animal's home cage. Mice were placed onto one side of the beam and were left to cross the beam to reach the cage. Mice that escaped into the cage were picked up and placed on the opposite side again for a total of three trials with $1 \mathrm{~min}$ intertrial intervals. Number of footslips for each mouse per trial was scored. Forceplate actometry, a sensitive and quantitative method (Fowler et al., 2001), was used to document changes in locomotor activity induced by injection of lentivirus expressing $\alpha$-synuclein mutants in substantia nigra. From the force plate traces/coordinate records, low-mobility bouts and spatial confinement per 6 min session were determined.

\section{Immunofluorescence and immunohistochemistry}

Cultured neurons infected with lentiviruses encoding myc-tagged $\alpha$-synuclein, or transfected HEK293T cells, were washed three times with PBS, and fixed for $20 \mathrm{~min}$ at room temperature in PBS containing 4\% paraformaldehyde. Following three washes with PBS, the fixed cultures were permeabilized for 5 min (PBS containing $0.1 \%$ Triton X-100, Sigma-Aldrich). Cells were washed three times with PBS and blocked for 20 min with 5\% BSA in PBS. $\alpha$-Synuclein expression was monitored using myc antibodies (monoclonal, 1:200; Santa Cruz Biotechnology). Synapsin antibodies (E028, polyclonal, 1:1000) were used as synaptic marker, incubated each overnight at $4^{\circ} \mathrm{C}$ in $1 \%$ BSA in PBS, and followed by anti-rabbit Alexa 633 and anti-mouse Alexa 488 secondary antibody (1:500 each), both incubated for $1 \mathrm{~h}$ each in blocking solution. The coverslips were rinsed six times with PBS, mounted on slides in Vectashield aqueous mounting medium (Vector Laboratories), and stored at $4^{\circ} \mathrm{C}$. Laser scanning confocal microscopy was performed to compare localization, with serial excitation at 488 and $633 \mathrm{~nm}$ on a Leica TCSSP-2 inverted microscope.

For immunohistochemical studies, anesthetized mice were perfused with ice-cold 4\% paraformaldehyde in PBS, followed by removal of the brain and overnight fixation in $4 \%$ paraformaldehyde in PBS (room temperature). Fixed brains were cryopreserved in 30\% sucrose in PBS for $2 \mathrm{~d}$ and frozen in Tissue-Tek Optimal Cutting Temperature embedding medium (Sakura Finetechnical). Sagittal brain sections $(20 \mathrm{~mm}$ ) were cut at $-20^{\circ} \mathrm{C}$ (Leica CM3050S cryostat), picked up on slides, and heat adhered at $37^{\circ} \mathrm{C}$ for $30 \mathrm{~min}$. For immunostaining, slides were incubated in blocking solution (3\% BSA, $0.1 \%$ Triton X-100 in PBS) for $1 \mathrm{~h}$ followed by overnight incubation with primary antibodies $\left(4^{\circ} \mathrm{C}\right)$. Slides were washed three times in PBS (5 min each) and incubated in blocking buffer 

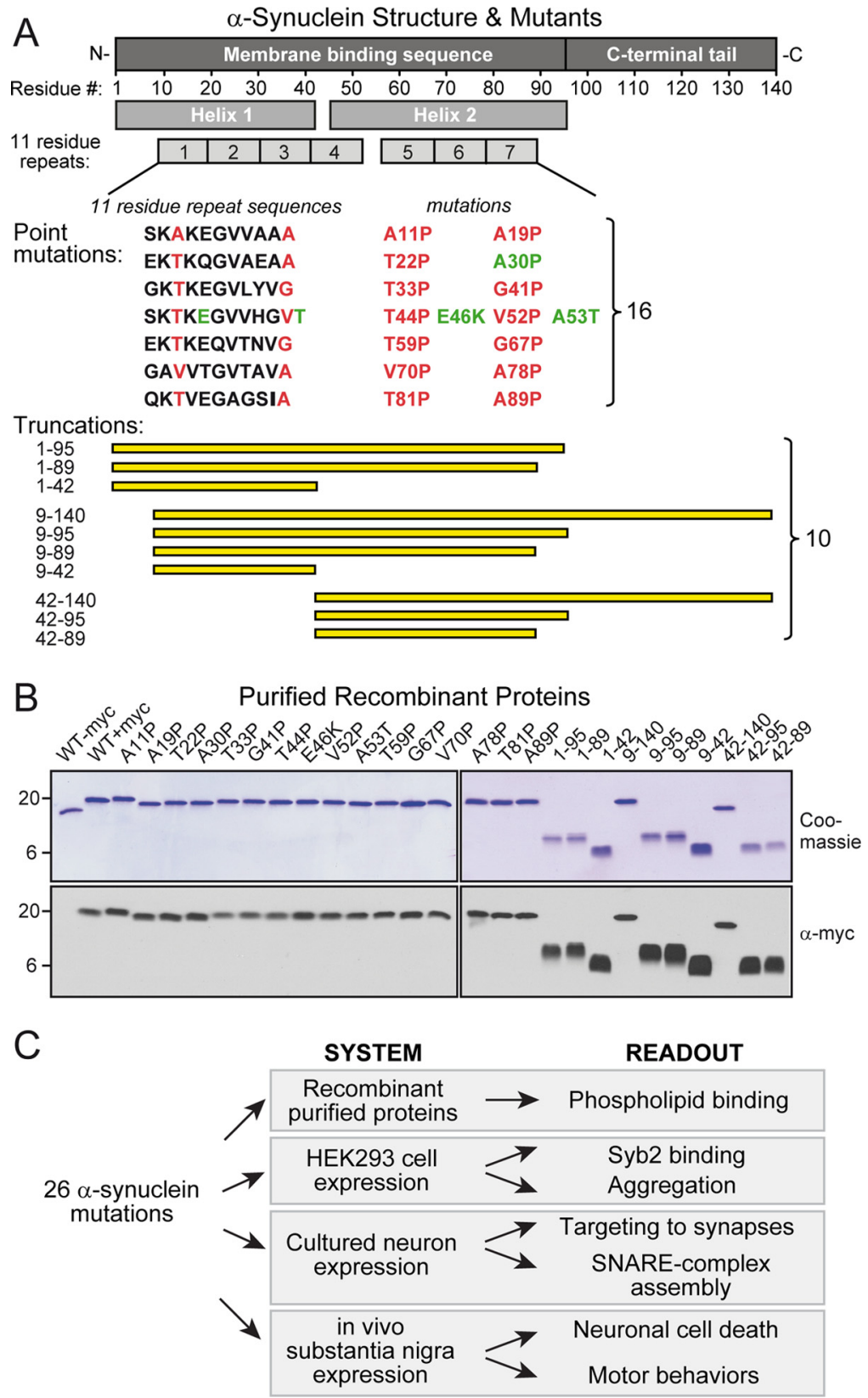

Figure 1. $\quad \alpha$-Synuclein mutagenesis strategy and experimental scheme. $\boldsymbol{A}$, Mutagenesis strategy. Mutagenesis of $\alpha$-synuclein was aimed at (1) introducing proline residues at conserved positions within the 11-mer sequences that comprise most of $\alpha$-synuclein to break amphiphatic helices that mediate the lipid binding of $\alpha$-synuclein (in red); (2) replicating PD mutants (in green); and (3) deleting subdomains by truncation mutations (yellow bars). $\boldsymbol{B}$, Purification of recombinant myc-tagged WT $\alpha$-synuclein and mutants of $\alpha$-synuclein (top, Coomassie staining; bottom, immunoblotting with c-myc antibody). C, Experimental scheme. WT and mutant $\alpha$-synucleins were subjected to a variety of in vitro and in vivo assays as depicted.

containing Alexa Fluor 488-coupled, 546-coupled, or 633-coupled secondary antibodies (Invitrogen) for $3 \mathrm{~h}$ at room temperature. Following six washes in PBS, slides were mounted with Vectashield hard-set mounting medium with DAPI (Vector Laboratories) followed by fluorescence microscopy.

All quantitations of immunofluorescence images were done with the image processing and analysis software ImageJ (National Institutes of Health). Synaptic colocalization in neuronal culture was assessed using Pearson's coefficient, with translated pictures used for background subtraction. In mouse brains injected with $\alpha$-synuclein-expressing lentiviruses, total tyrosine hydroxylase (TH)-positive neurons, NeuN-positive puncta, and DAPI puncta were counted in each section containing GFP fluorescence. NeuN puncta were normalized to total DAPI puncta in the same brain section. Image acquisition and thresholding parameters were kept constant across each experiment.

\section{Immunoblotting}

and immunoprecipitation

Either transfected HEK293T cells or cultured neurons were solubilized in PBS, pH 7.4, containing $0.15 \%$ Triton $\mathrm{X}-100$ and protease inhibitors (Roche). Following centrifugation at $16,000 g_{\text {av }}$ for $20 \mathrm{~min}$ at $4^{\circ} \mathrm{C}$, the clarified lysate was used for immunoblotting (after addition of $2 \times$ SDS sample buffer containing $100 \mathrm{~mm}$ DTT) or subjected to immunoprecipitation. Immunoprecipitation was performed with the indicated primary antibodies and $50 \mu \mathrm{l}$ of a $50 \%$ slurry of protein-A Sepharose beads (GE Healthcare) for $2 \mathrm{~h}$ at $4^{\circ} \mathrm{C}$. Control immunoprecipitations were performed with preimmune sera. Following five washes with $1 \mathrm{ml}$ of the extraction buffer, bound proteins were eluted with $2 \times$ SDS sample buffer containing $100 \mathrm{~mm}$ DTT and boiled for $20 \mathrm{~min}$ at $100^{\circ} \mathrm{C}$. Coprecipitated proteins were separated by SDS-PAGE, with $5 \%$ of the input in the indicated lane.

To retain $\alpha$-synuclein truncations on the nitrocellulose membranes, membranes were dried for $1 \mathrm{~h}$ at room temperature and fixed for $15 \mathrm{~min}$ at room temperature in $0.2 \%$ glutaraldehyde in PBS. Membranes were washed $3 \times$ with TBS-T and treated as above.

Quantitation of SNARE-complexes as high molecular mass bands

Whole brains or cortices were homogenized in ice-cold PBS, and immediately dissolved in $2 \times$ SDS sample buffer. The lysates were subjected to SDS-PAGE and immunoblotting with antibodies to SNAP-25 (SMI81) and polyclonal antibodies to synaptobrevin-2 (P939) and syntaxin-1 (438B). To measure total SNARE protein levels, samples were boiled for $20 \mathrm{~min}$ at $100^{\circ} \mathrm{C}$. SDS-resistant SNARE-complexes were defined as the immunoreactive material $>40 \mathrm{kDa}$ that was absent from boiled samples (Hayashi et al., 1994).

\section{Recombinant $\alpha$-synuclein expression}

All proteins were expressed in bacteria (BL21 strain) as GST fusion proteins in modified pGEX-KG vectors (GE Healthcare), essentially as described previously (Burré et al., 2010). Bacteria were grown to optical density of 0.5 (measured at $600 \mathrm{~nm}$ ), and protein expression was induced with $0.05 \mathrm{~mm}$ isopropyl-Dthiogalactopyranoside (IPTG) for $6 \mathrm{~h}$ at room temperature. Bacteria were harvested by centrifugation for $20 \mathrm{~min}$ at $4000 \mathrm{rpm}$ and $4^{\circ} \mathrm{C}$, and pellets were resuspended in solubilization buffer [PBS, $0.5 \mathrm{mg} / \mathrm{ml}$ lysozyme, $1 \mathrm{~mm}$ PMSF, 1 mm EDTA, DNase, and an EDTA-free protease inhibitor mixture (Roche)]. Cells were broken by sonication $(3 \times 15$ pulses, $50 \%$ output), and insoluble material was removed by centrifugation for 20 $\min$ at $7000 g_{\text {av }}$ at $4^{\circ} \mathrm{C}$. Proteins were affinity-purified using glutathione Sepharose bead (GE Healthcare) incubation overnight at $4^{\circ} \mathrm{C}$, followed by TEV cleavage ( $10 \mathrm{U} / \mathrm{mg}$ protein) for $4 \mathrm{~h}$ at $22^{\circ} \mathrm{C}$.

\section{Lipid binding}

Liposome preparation. Liposomes were always prepared on the day of usage, essentially as described previously (Burré et al., 2010). Either 500 
A

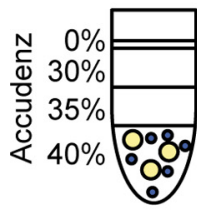
$30 \mu \mathrm{l}$ $200 \mu \mathrm{l}$ $200 \mu \mathrm{l}$ $400 \mu \mathrm{l}$

C
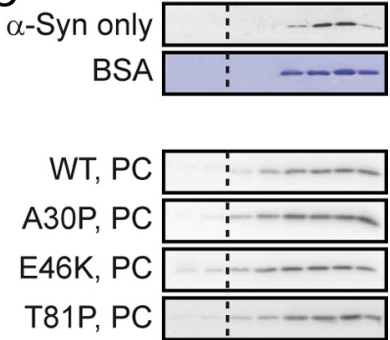

$E$

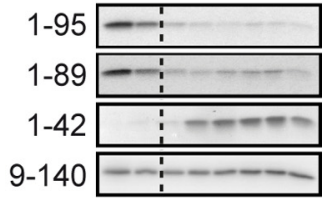

B

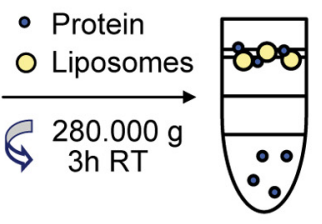

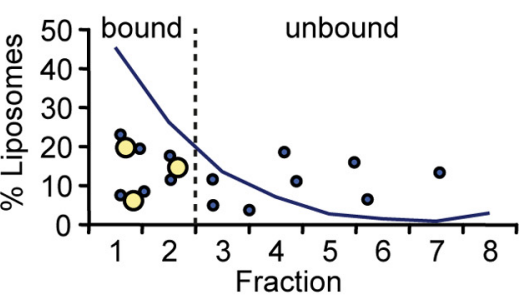

D

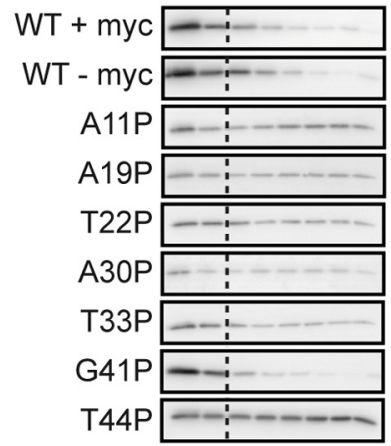

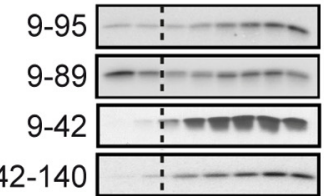

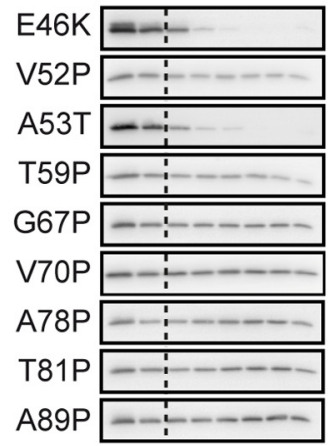

42-95

$42-89$

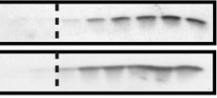

$\mathrm{F}$

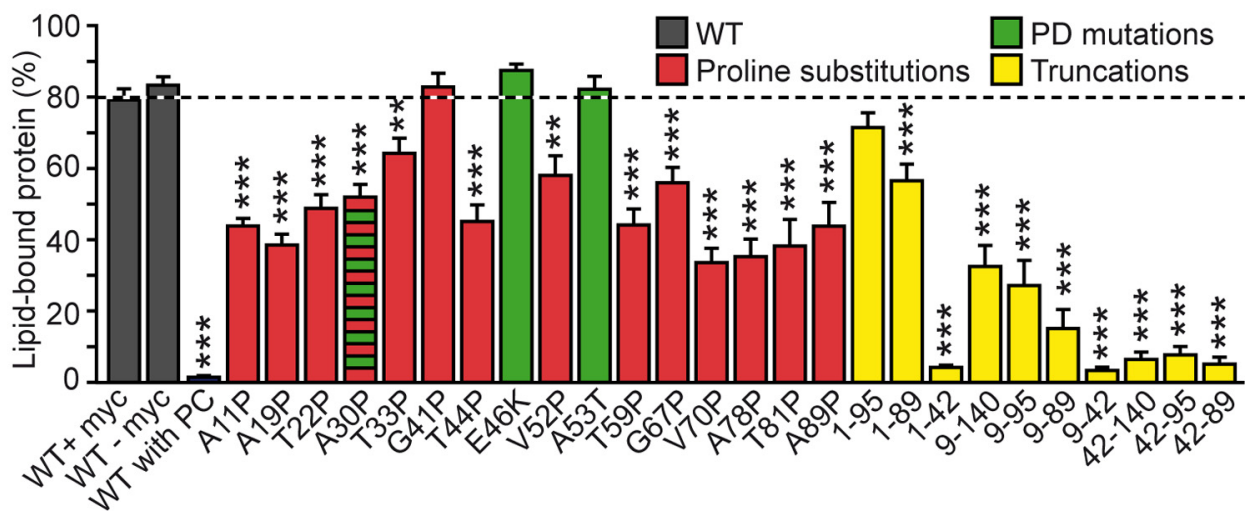

Figure2. Binding of $\alpha$-synuclein mutants to phospholipid membranes. $A, B$, Phospholipid binding assay. Liposomes mixed with WT and mutant $\alpha$-synuclein were floated by density gradient centrifugation (A). Based on liposome distribution in the gradient (B), the top two fractions 1 and 2 were defined as lipid-bound fractions. $\boldsymbol{C}$, Lack of flotation of BSA and of $\alpha$-synuclein in the absence of liposomes or with uncharged liposomes, analyzed by Coomassie staining or by immunoblotting with antibodies to the myc-epitope fused to $\alpha$-synuclein. $\boldsymbol{D}-\boldsymbol{F}$, Quantitation of phospholipid binding by WT and mutant $\alpha$-synuclein. Flotation of $\alpha$-synuclein point mutants $(\boldsymbol{D})$ and truncations $(\boldsymbol{E})$ with liposomes was quantitated as the sum of the top two fractions, and was plotted as the percentage of total $\alpha$-synuclein in the gradient $(\boldsymbol{F})$. Data are means \pm SEM $\left(* * p<0.01,{ }^{* * *} p<0.001\right.$ by Student's $t$ test $; n=6-8$ independent experiments).

$\mu \mathrm{g}$ brain L- $\alpha$-phosphatidylcholine (PC, Avanti Polar Lipids) or $345 \mu \mathrm{g}$ of PC and $155 \mu \mathrm{g}$ of brain L- $\alpha$-phosphatidylserine (Avanti Polar Lipids) were mixed with $2.5 \mu \mathrm{g}$ of 1-oleoyl-2-\{6-[(7-nitro-2-1,3-benzoxadiazol4-yl)amino]hexanoyl -sn-glycero-3-phosphocholine (NBD, Avanti Polar Lipids) in a glass tube. The lipid mixture was dried under a nitrogen stream and for $2 \mathrm{~h}$ in a speed vacuum concentrator. To form unilamellar small vesicles, dried lipids were solubilized in $500 \mu \mathrm{l}$ of $20 \mathrm{~mm}$ phosphate buffer, $\mathrm{pH} 7.4$, vortexed for $2 \mathrm{~min}$, and then sonicated for $3 \times 15$ pulses at $1 \mathrm{~s}$ intervals and $38 \%$ sonicator output.

Lipid-binding assay. At room temperature, $3.5 \mu \mathrm{M} \alpha$-synuclein was incubated with liposomes at 1:363 molar ratio for $2 \mathrm{~h}$. In a centrifugation tube, $100 \mu$ l of protein sample was mixed with $100 \mu$ l of $20 \mathrm{~mm}$ phosphate buffer, $\mathrm{pH} 7.4$, and $200 \mu \mathrm{l}$ of $80 \%$ Accudenz reagent (Accurate Chemical $\&$ Scientific) in the same buffer ( $40 \%$ final density), and carefully overlaid with $200 \mu \mathrm{l}$ of $35 \%$ Accudenz reagent, $200 \mu \mathrm{l}$ of 30\% Accudenz reagent, and $30 \mu \mathrm{l}$ of buffer. To achieve separation of bound and nonbound proteins, gradients were centrifuged for $3 \mathrm{~h}$ at $280,000 \mathrm{~g}_{\mathrm{av}}$ and $100 \mu \mathrm{l}$ of fractions were collected from the top to the bottom of the gradient. The distribution of the liposomes in the gradient was determined by measuring the fluorescence of the lipid derivative NBD in each fraction using a fluorescence plate reader (excitation at $464 \mathrm{~nm}$, emission at $531 \mathrm{~nm}$; Mithras LB 940, Berthold Technologies). For analysis of protein distribution within the gradient, $10 \mu \mathrm{l}$ of $5 \times$ SDS sample buffer containing 100 mM DTT were mixed with $100 \mu \mathrm{l}$ of protein sample, and $20 \mu \mathrm{l}$ were separated by SDS-PAGE and immunoblotted for SNARE proteins and $\alpha$-synuclein.

\section{Protein quantitation}

All quantitative immunoblotting experiments were performed with iodinated secondary antibodies as described previously (Rosahl et al., 1995). Samples were separated by SDS-PAGE, and transferred onto nitrocellulose membranes. Blots were blocked in Tris-buffered saline con- 
A

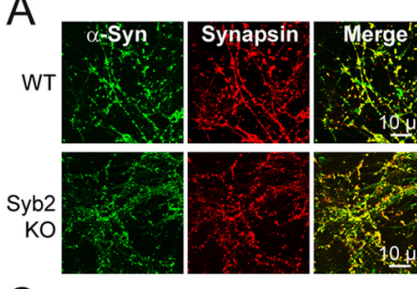

C
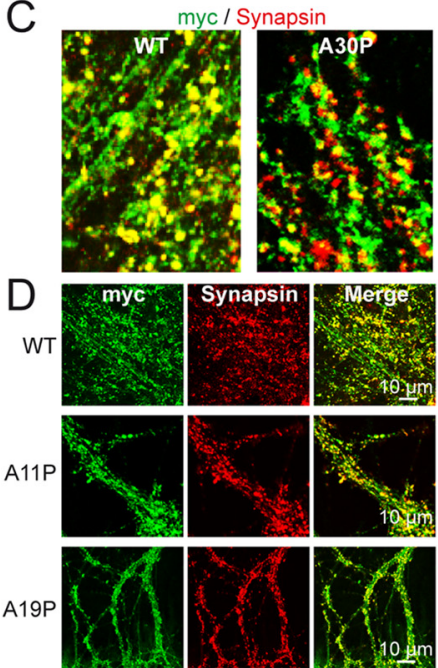

T22P
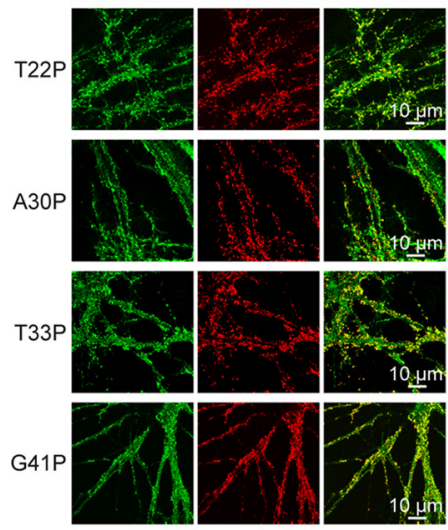
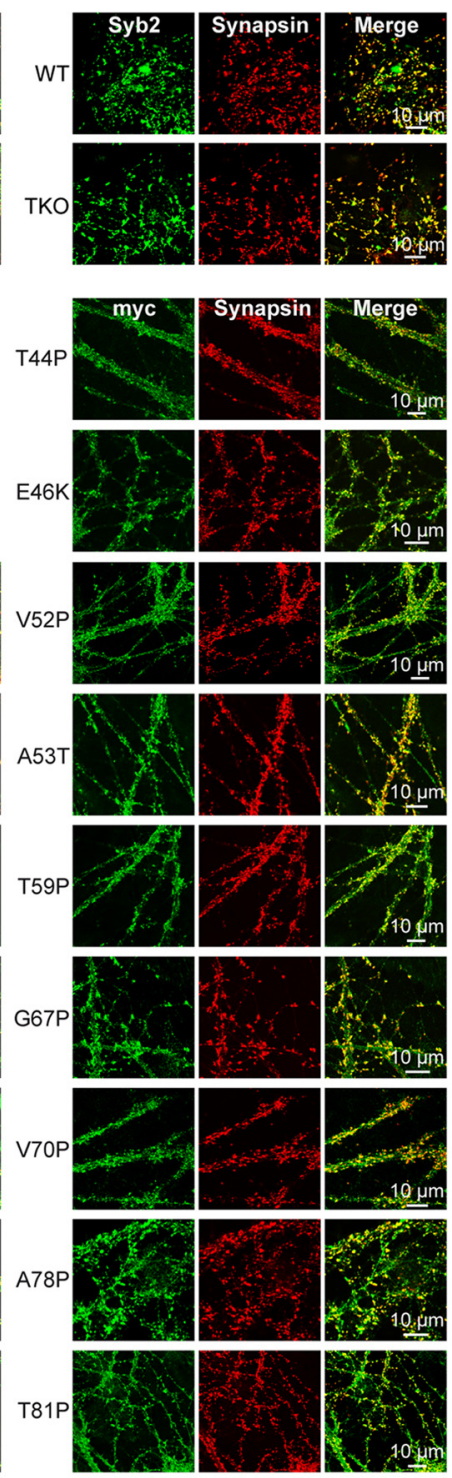

E

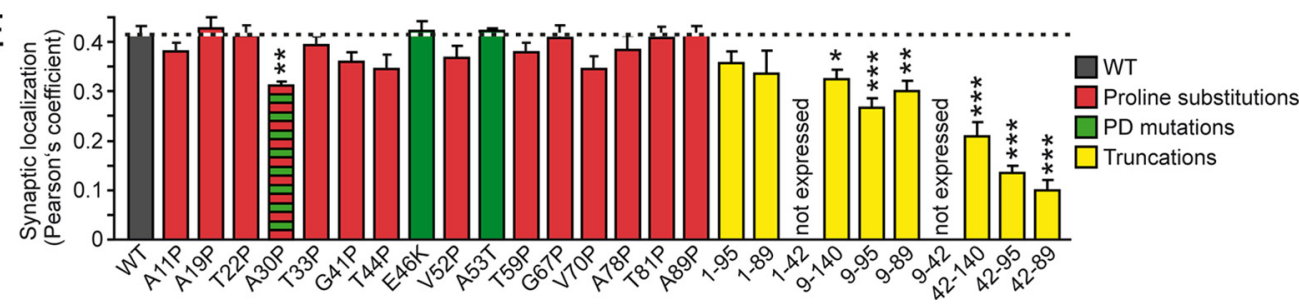

Figure 3. Synaptic targeting of $\alpha$-synuclein mutants. $\boldsymbol{A}, \boldsymbol{B}$, Synaptic localization of $\alpha$-synuclein in cultured neurons from WT and synaptobrevin-2 KO (Syb2 K0) mice, and of Syb2 in cultured neurons from WT and synuclein triple knock-out (TKO) mice $(\boldsymbol{A})$. Cultured neurons were immunostained with antibodies to endogenous $\alpha$-synuclein (left, green), endogenous Syb2 (right, green), and synapsin (red). Colocalization was quantitated using Pearson's coefficient (B). C $\boldsymbol{E}$, Synaptic localization of WT and mutant $\alpha$-synucleins. Hippocampal WT cultures were infected with lentivirus expressing WT and mutant $\alpha$-synucleins at 7 DIV, and were immunostained at 21 DIV using antibodies to c-myc (green) and to synapsin (as a synaptic marker, red). C shows magnified images of WT and A30P $\alpha$-synuclein to highlight differences in synaptic targeting. Synaptic localization was quantitated using Pearson's coefficient $(\boldsymbol{E})$. Note that deletion mutants $1-42$ and $9-42$ were not expressed. Data are means \pm SEM $\left({ }^{*} p<0.05,{ }^{* *} p<0.01,{ }^{* * *} p<0.001\right.$ by Student's $t$ test; $n=3$ independent cultures for $\boldsymbol{A}$, and $n=7-9$ independent cultures for $\boldsymbol{D}$ ).

taining $0.1 \%$ Tween-20 (Sigma-Aldrich) and 3\% fat-free milk for $30 \mathrm{~min}$ at room temperature. The blocked membrane was incubated in blocking buffer containing primary antibody overnight at $4^{\circ} \mathrm{C}$, followed by three washes in blocking buffer. The washed membrane was incubated in blocking buffer containing either horseradish peroxidase (HRP)-conjugated secondary antibody (1:8000; MP Biomedicals) for $1 \mathrm{~h}$ at room temperature, or ${ }^{125}$ I-labeled secondary antibody (1:1000; PerkinElmer) overnight at room temperature. HRP immunoblots were developed using enhanced chemilu- minescence (GE Healthcare). ${ }^{125} \mathrm{I}$ blots were exposed to a PhosphorImager screen (GE Healthcare) overnight and scanned using a Typhoon scanner (GE Healthcare), followed by quantitation with ImageQuant software (GE Healthcare).

\section{Antibodies}

Monoclonal antibodies used were $\beta$-actin (1:5000; A1978, Sigma-Aldrich), myc (1:200; Santa Cruz Biotechnology), NeuN (MAB377, Millipore), 

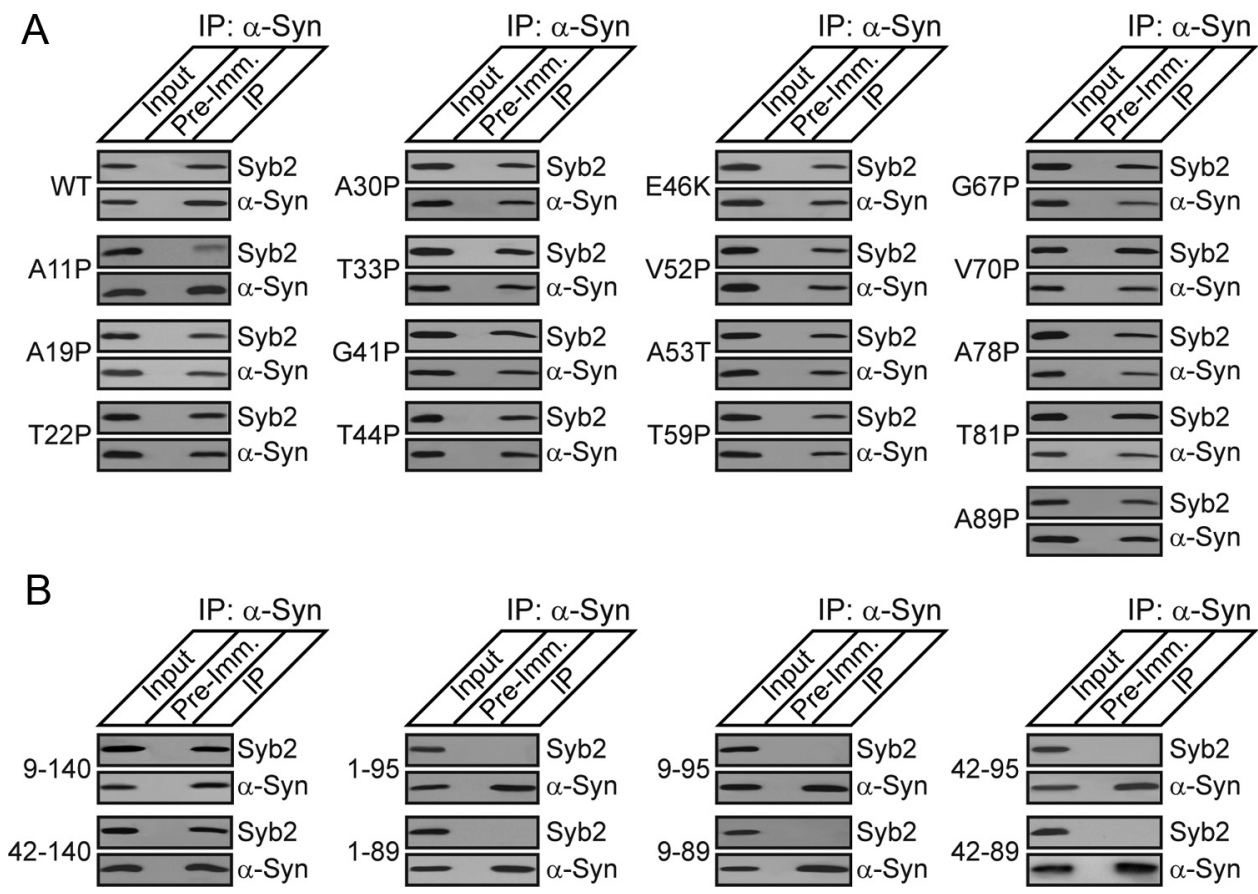

Figure 4. Synaptobrevin-2 binding by $\alpha$-synuclein mutants. Equal amounts of DNA for synaptobrevin-2 (Syb2) and either myc-tagged WT $\alpha$-synuclein ( $\alpha$-Syn) and $\alpha$-synuclein point mutants (A) or $\alpha$-synuclein deletion mutants (B) were cotransfected into HEK293T cells. $\alpha$-Synuclein in cell lysates was immunoprecipitated with preimmune serum (Pre-Imm.) or with antibodies to the myc epitope tag (IP), and the input and the immunoprecipitates were analyzed by immunoblotting with antibodies to synaptobrevin-2 (Syb2) or $\alpha$-synuclein ( $\alpha$-Syn).

SNAP-25 (1:5000; SMI81, Sternberger Monoclonals; 1:1000; cl. 71.1, Synaptic Systems), synaptobrevin-2 (1:1000; cl. 69.1, Synaptic Systems), $\alpha$-synuclein (1:1000; BD Biosciences), syntaxin-1 (1:1000; cl. HPC-1, Synaptic Systems). Polyclonal antibodies used were myc (1:1000; SigmaAldrich), synapsin (1:1000; E028), syntaxin-1 (1:1000; 438B), and TH (1: 400; AB112, Abcam).

Quantitation of functional and pathological indices

Average function was calculated from data obtained for lipid binding (percentage of WT), synaptic targeting (percentage of WT), synaptobrevin-2 binding (100 or $0 \%$ ), and SNARE-complex assembly (percentage of WT). Average pathology was calculated from data obtained for aggregation in transfected HEK cells ( percentage of WT), beamwalk analysis ( percentage of WT), spatial confinement and low-mobility bouts obtained by force plate analysis ( percentage of WT), and analysis of dopaminergic and total neuron loss in substantia nigra ( percentage of WT).

Statistical analyses

Unless stated otherwise, coimmunoprecipitation experiments are shown as recovered protein (relative to the input), which was first normalized to the immunoprecipitated protein and then normalized to the control. All other data shown are means \pm SEMs, and were statistically analyzed by Student's unpaired two-tailed $t$ test to compare the data groups. $n$ refers to the number of different cultures or mice used in each group in separate experiments, or to the number of independent in vitro experiments.

\section{Results}

Design and generation of $\alpha$-synuclein mutants

$\alpha$-Synuclein is a small protein (140 residues) composed of an $\mathrm{N}$-terminal region (residues $1-95$ accounting for $\sim 2 / 3$ of the molecule), which binds to membranes in an $\alpha$-helical conformation, and a C-terminal region (residues 96-140), which remains unstructured upon membrane-binding, but is phosphorylated and binds to synaptobrevin-2 (Fig. 1) (Okochi et al., 2000; Fujiwara et al., 2002; Kahle et al., 2002; Anderson et al., 2006; Beyer, 2006; McFarland et al., 2008; Paleologou et al., 2008; Waxman and Giasson, 2008; Burré et al., 2010; Paleol- ogou et al., 2010). The $\mathrm{N}$-terminal region of $\alpha$-synuclein contains seven imperfect 11 aa repeats with a KTKEGV consensus sequence. Upon membrane binding, the $\mathrm{N}$-terminal region forms either two $\alpha$-helices connected by a flexible linker or a single extended $\alpha$-helix with a possible continuous switch between the two states under physiological conditions (Chandra et al., 2003; Bisaglia et al., 2005; Ulmer et al., 2005; Borbat et al., 2006; Bortolus et al., 2008; Georgieva et al., 2010; Lokappa and Ulmer, 2011).

To investigate the relationship between the physiological function of $\alpha$-synuclein in SNARE-complex assembly and its pathological effects in neurons, we systematically mutated key residues and sequences of human $\alpha$-synuclein (Fig. $1 A$ ). We generated two types of $\alpha$-synuclein mutations: (1) point mutations that introduce proline substitutions at defined positions in the 11 aa repeats to impair $\alpha$-helix formation or to replicate PD mutations, and (2) deletion mutations that remove parts of the overall protein (Fig. $1 A$ ). In this manner, we produced 26 different $\alpha$-synuclein mutants. All $\alpha$-synuclein mutants were tagged with a myc epitope to allow accurate quantitation of the levels of the various mutant proteins (Fig. $1 B$ ). We then examined all $\alpha$-synuclein mutants by seven assays that range from experiments using purified proteins in in vitro systems to experiments in cultured neurons and in vivo in mice, thus producing 189 principal measured parameters (Fig. $1 C)$. These seven assays include analyses of the biochemical activities of $\alpha$-synuclein (phospholipid binding, aggregation, and synaptobrevin-binding), the targeting of $\alpha$-synuclein and its mutants to synapses, analysis of their effects on SNARE-complex assembly, and examination of the in vivo effects of lentivirally expressed $\alpha$-synuclein and its mutants (Fig. 1C).

Lipid binding of $\alpha$-synuclein is mediated by its two $\alpha$-helices $\alpha$-Synuclein cycles between a cytosolic monomeric state and a membrane-bound state that localizes $\alpha$-synuclein to synaptic vesicles (Iwai et al., 1995). Thus, any change in membrane affinity 
A
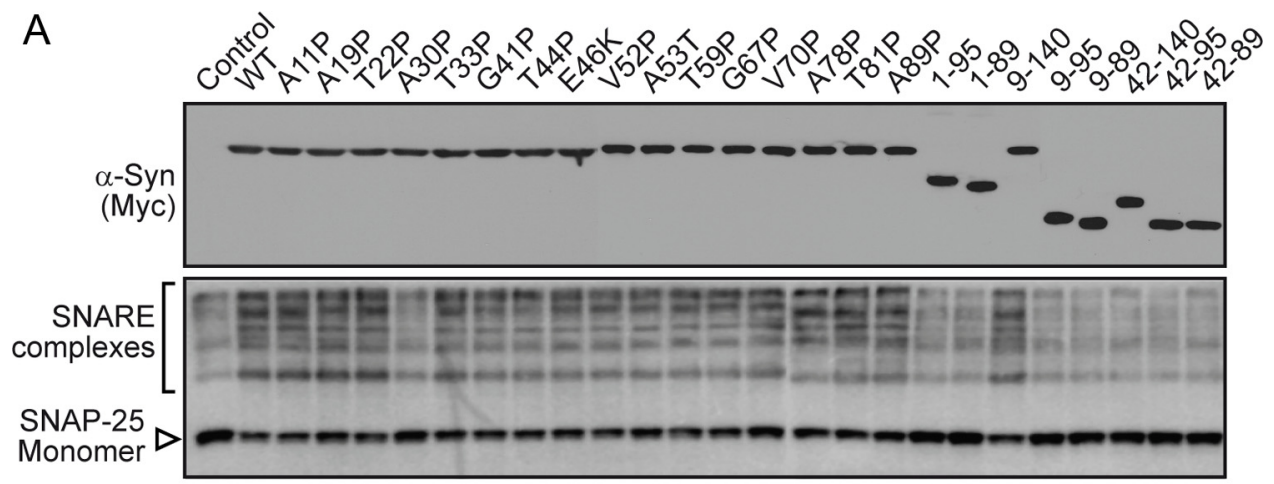

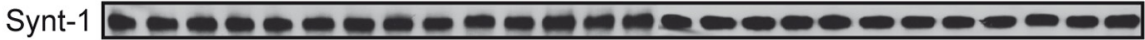

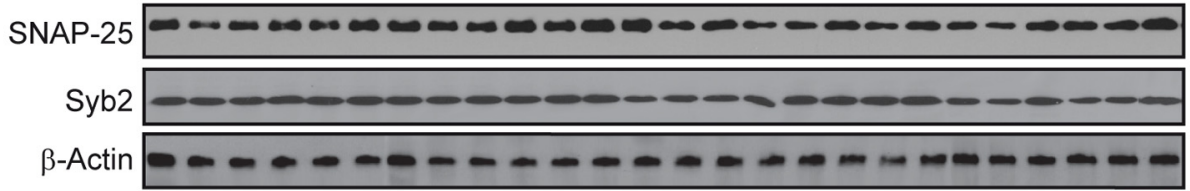

$\mathrm{B}$

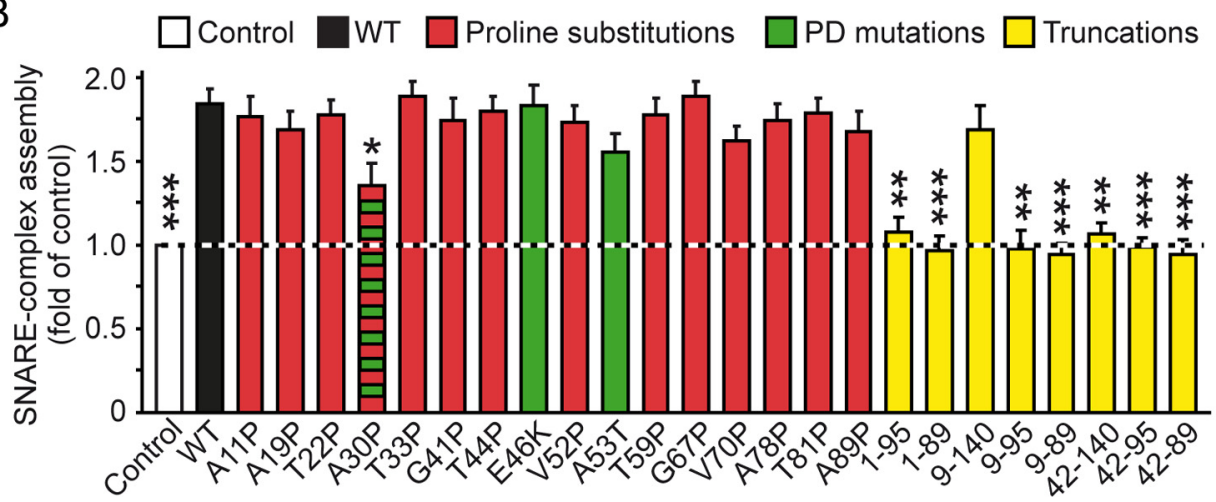

Figure 5. Effects of $\alpha$-synuclein mutations on the $\alpha$-synuclein mediated catalysis of SNARE-complex assembly measured via the SDS-resistance of SNARE complexes. $\boldsymbol{A}, \boldsymbol{B}$, Cultured neurons from synuclein triple K0 (TKO) mice were infected at 7DIV with lentivirus overexpressing WT and mutant $\alpha$-synuclein. At 21 DIV, neurons were harvested and SNARE-complexes were measured as the high molecular mass bands immunoreactive for SNAP-25, which disappear upon boiling. $\alpha$-Syn, $\alpha$-synuclein; Synt-1, syntaxin-1; Syb2, synaptobrevin-2. B, Quantitation of SNARE-complex assembly upon overexpression of WT and mutant $\alpha$-synucleins, normalized to control levels. Data are means $\pm \operatorname{SEM}\left({ }^{*} p<0.05,{ }^{* *} p<0.01,{ }^{* * *} p<0.001\right.$ by Student's t test; $n=3$ independent cultures).

may alter its function. To measure the ability of point and truncation mutants of $\alpha$-synuclein to bind to phospholipid vesicles, we used purified myc-tagged $\alpha$-synuclein proteins (Fig. $1 B$ ) and a previously described liposome flotation assay (Fig. 2A,B) (Burré et al., 2010). When $\alpha$-synuclein was assayed without liposomes or in the presence of phosphatidylcholine liposomes, which are not negatively charged, no shift of $\alpha$-synuclein to the liposome-containing top gradient fractions was detected (Fig. $2 C)$. Upon introduction of $30 \%$ phosphatidylserine into phosphatidylcholine liposomes, the majority of WT $\alpha$-synuclein was present in the liposome fraction, unaffected by the presence or absence of the N-terminal myc epitope-tag (Fig. 2D). All proline mutations except for G41P reduced the ability of $\alpha$-synuclein to bind to phospholipid vesicles, presumably due to breaking one of the two $\alpha$-helices (Chandra et al., 2003; Bussell and Eliezer, 2004; Ulmer and Bax, 2005), whereas the two PD mutations A53T and E46K did not impair lipid binding (Fig. 2D). Deletion of the unstructured C terminus of $\alpha$-synuclein had no effect on lipid binding, but deletion of either one of the two $\alpha$-helices abolished lipid binding (Fig. 2E). Notably, deletion of the N-terminal 7 residues that precede the first 11 aa repeat of $\alpha$-synuclein also dramatically reduced lipid binding (Fig. 2E). These liposomebinding results were quantified in multiple independent experiments, enabling an accurate determination of the percentage of total protein that was bound (Fig. $2 F$ ). The quantitations revealed that, although the proline mutations impair phospholipid binding, they do not block binding in the same manner as complete deletions of one of the two $\alpha$-helices, suggesting that the proline mutations only decrease the affinity of $\alpha$-synuclein for phospholipids, but do not abolish binding. These quantitations also indicate that proline mutations in all parts of the two $\alpha$-helices have similar detrimental effects (except for the G41P mutation, which appeared to be innocuous), suggesting that both $\alpha$-helices of $\alpha$-synuclein and all segments of these $\alpha$-helices are equally important for phospholipid binding.

Effect of $\alpha$-synuclein mutations on $\alpha$-synuclein localization $\alpha$-Synuclein is highly enriched in presynaptic terminals (Iwai et al., 1995), consistent with its role in promoting SNARE-complex assembly (Burré et al., 2010). Immunolocalization studies in cultured neurons from WT mice revealed a high degree of $\alpha$-synuclein colocalization with the synaptic vesicle marker synapsin, measured using Pearson's coefficient (Fig. 3A,B). The $\alpha$-synuclein colocalization was almost as high as that of the synaptic vesicle protein synaptobrevin-2. In cultured neurons from synaptobrevin-2 KO mice (Schoch et al., 2001), the synaptic localization of $\alpha$-synuclein was significantly decreased (Fig. $3 A, B$ ). However, no change in synaptobrevin-2 localization was de- 

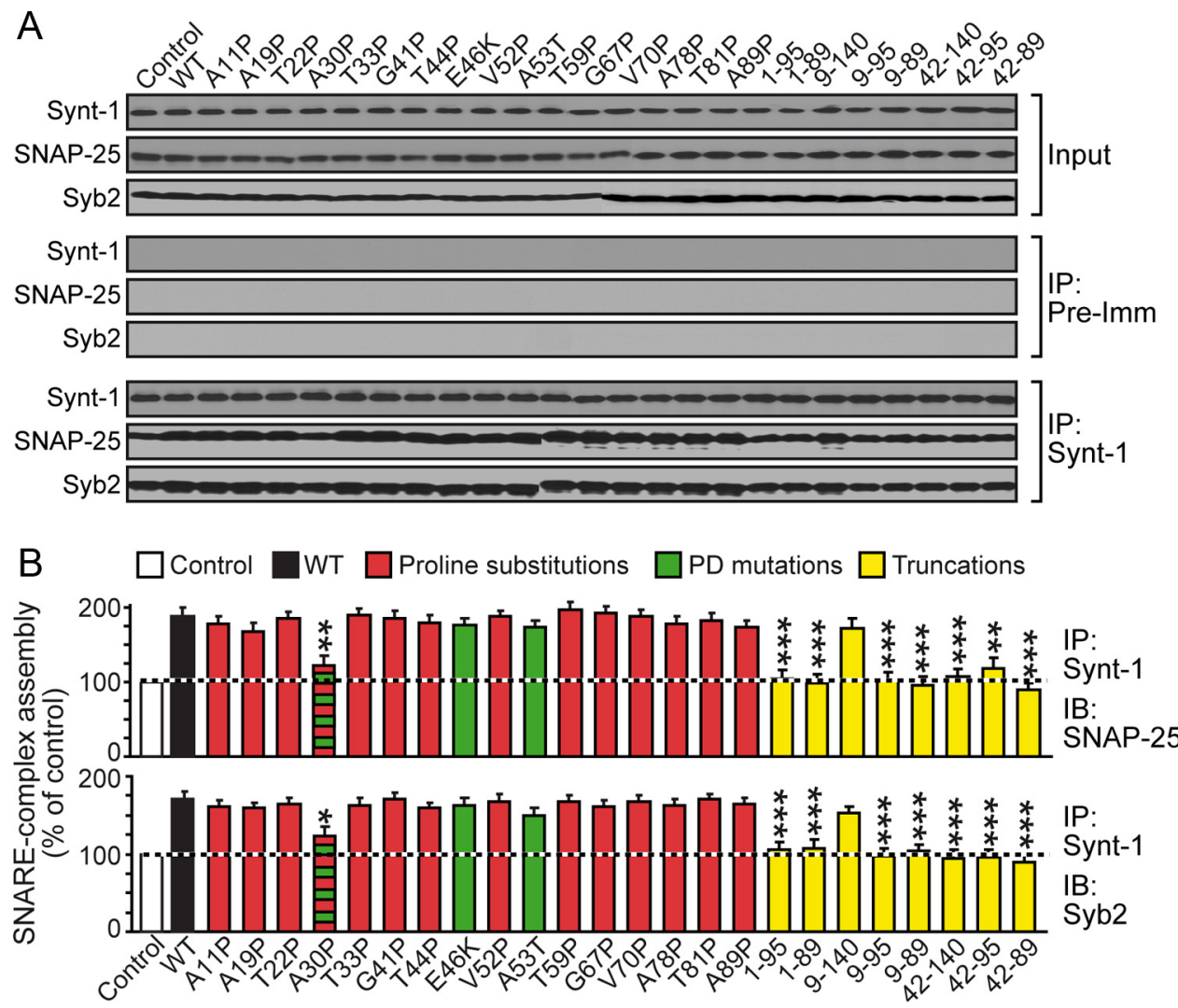

Figure 6. Effects of $\alpha$-synuclein mutations on the $\alpha$-synuclein mediated catalysis of SNARE-complex assembly measured by SNARE protein coimmunoprecipitations. $\boldsymbol{A}, \boldsymbol{B}$, Cultured neurons obtained as described for Figure 5 were harvested at 21 DIV, and SNARE-complexes were immunoprecipitated with antibodies to syntaxin-1 (Synt-1). Coimmunoprecipitated proteins were immunoblotted for SNAP-25 and synaptobrevin-2 (Syb2) ( $\boldsymbol{A}$ ). Recovered protein (relative to input) was quantitated and normalized to the immunoprecipitated protein and then to control levels ( $\boldsymbol{B}$ ). Data are means \pm SEM $\left({ }^{*} p<0.05,{ }^{* *} p<0.01,{ }^{* * *} p<0.001\right.$ by Student's $t$ test; $n=3$ independent cultures $)$.

tected in neurons from $\alpha / \beta / \gamma$-synuclein triple KO mice. Together, these experiments not only support the preferential localization of $\alpha$-synuclein in presynaptic terminals adjacent to synapsin, but also suggest that this localization depends, at least in part, on the binding of $\alpha$-synuclein to synaptobrevin-2 (Burré et al., 2010), whereas the localization of synaptobrevin-2 is independent of synucleins.

We then asked which $\alpha$-synuclein sequences may be necessary for its presynaptic localization. To address this question, we expressed WT $\alpha$-synuclein and the $26 \alpha$-synuclein mutants in cultured cortical mouse neurons using lentiviral infection at 7 DIV, and analyzed the localization of the expressed $\alpha$-synuclein proteins by immunocytochemistry at 21 DIV (Fig. 3C,D). These experiments were independently repeated multiple times and quantified by image analysis in a blinded manner, allowing a numerical description of the degree of presynaptic targeting of each $\alpha$-synuclein mutant (Fig. $3 E$ ).

Exogenous WT myc-tagged $\alpha$-synuclein exhibited the same degree of colocalization with endogenous synapsin as endogenous $\alpha$-synuclein (Fig. 3B,E). Surprisingly, most proline mutants that had a profound effect on lipid binding produced at best a marginal decrease in the presynaptic targeting of $\alpha$-synuclein. Only the PD mutant A30P showed a significant $(\sim 25 \%)$ reduction of presynaptic targeting (Fig. 3C-E), suggesting an additional defect besides the impaired lipid binding. Most truncation mutants, however, significantly decreased the presynaptic localization of $\alpha$-synuclein, demonstrating that both $\alpha$-helices of $\alpha$-synuclein are essential for $\alpha$-synuclein targeting to synaptic vesicles (Fig. 3D,E).
The C-terminal $\alpha$-synuclein sequence is essential for synaptobrevin-2 binding and for promoting SNARE-complex assembly

To test which $\alpha$-synuclein mutations impair binding to synaptobrevin-2, we transfected HEK293T cells with expression vectors encoding synaptobrevin- 2 and WT or mutant $\alpha$-synucleins, and analyzed their interaction using coimmunoprecipitation with antibodies to the myc epitope-tag on the transfected $\alpha$-synucleins (Fig. 4). No point mutation impaired the coimmunoprecipitation of synaptobrevin-2 with $\alpha$-synuclein (Fig. 4A). In contrast but in agreement with previous studies (Burré et al., 2010), truncation mutants lacking the C-terminal $\alpha$-synuclein region did not bind to synaptobrevin-2, whereas truncation mutants of the $\mathrm{N}$-terminal region had no effect (Fig. 4B).

We next probed the ability of various $\alpha$-synuclein mutants to promote SNARE-complex assembly similar to WT $\alpha$-synuclein. To analyze the effect of $\alpha$-synuclein mutants on SNARE-complex assembly, we expressed the various $\alpha$-synuclein proteins by lentiviral delivery in cultured neurons obtained from triple $\alpha / \beta / \gamma$-synuclein KO mice. We then assayed SNARE-complex assembly using two independent methods: (1) immunoblotting of SDS-resistant SNARE-complexes on SDS-polyacrylamide gels (Hayashi et al., 1994) and (2) coimmunoprecipitating the SNARE proteins synaptobrevin-2 and SNAP-25 with antibodies to the SNAREprotein syntaxin-1 (Figs. 5, 6). For both assays, we used quantitative immunoblotting with ${ }^{125}$ I-labeled secondary antibodies to measure the levels of the indicated proteins.

Both assays produced the same results. Whereas WT $\alpha$-synuclein potently promoted SNARE-complex assembly as reported previ- 
A
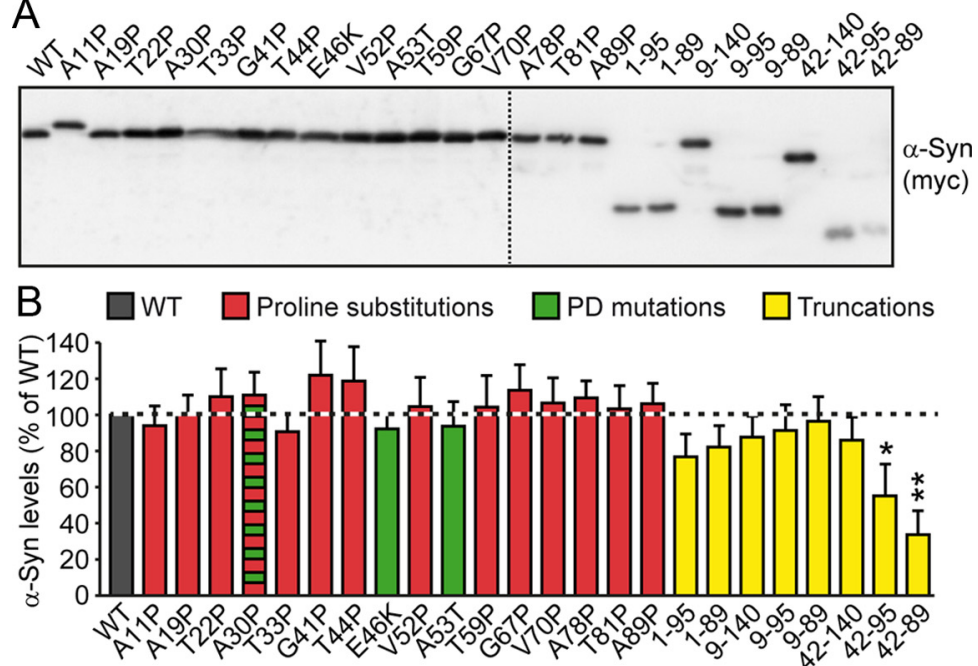

C
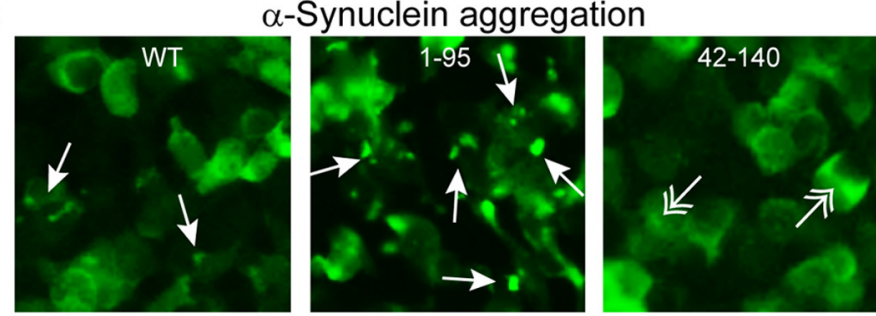

D
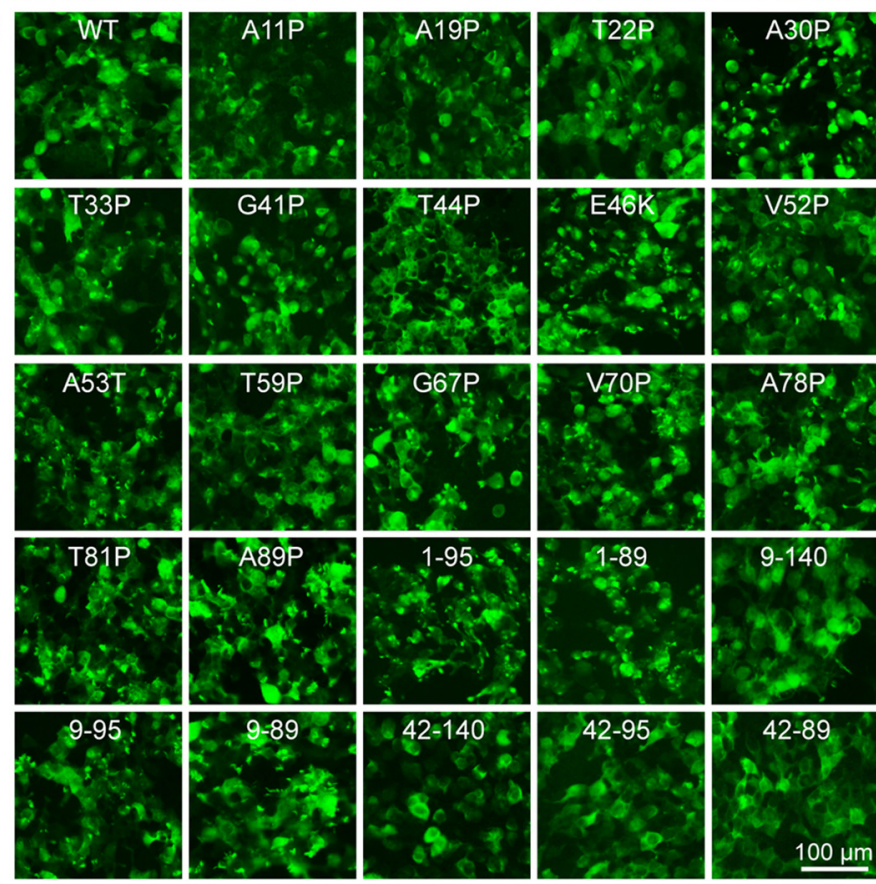

E
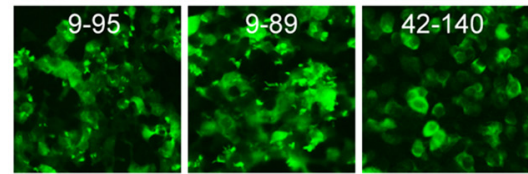

Proline substitutions

$\square$ PD mutations

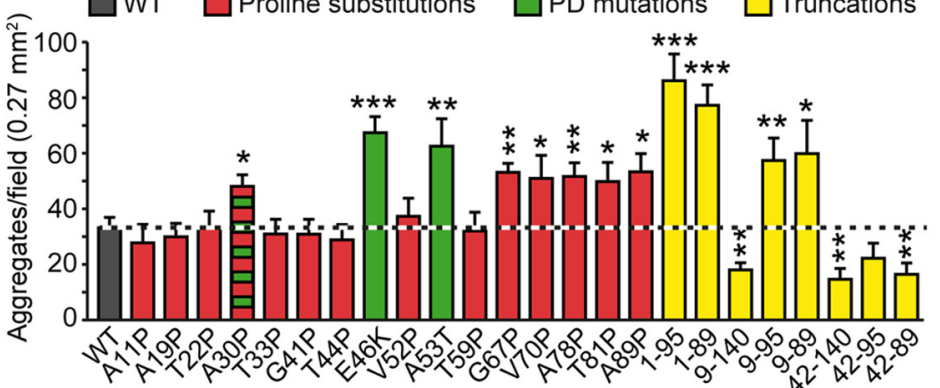

Figure 7. Aggregation propensity of WT and mutant $\alpha$-synucleins. $\boldsymbol{A}, \boldsymbol{B}$, Expression of WT and mutant $\alpha$-synucleins in HEK293T cells ously (Burré et al., 2010), all truncation mutants except for the deletion of the $\mathrm{N}$-terminal $8 \alpha$-synuclein residues were unable to promote SNARE-complex assembly (Figs. 5, 6). Thus, both phospholipid binding mediated by the $\alpha$-helices of $\alpha$-synuclein and synaptobrevin-2 binding mediated by the C-terminal $\alpha$-synuclein sequence (Figs. 2, 4) are required for the ability of $\alpha$-synuclein to promote SNAREcomplex assembly. In contrast to the truncation mutants, only one point mutant of $\alpha$-synuclein, the A30P mutation, impaired the ability of $\alpha$-synuclein to promote SNARE-complex assembly. The others, including the PD mutants E46K and A53T, did not. Thus, partial impairment of phospholipid binding, as observed with most of these point mutants (Fig. 2), does not by itself block the function of $\alpha$-synuclein to promote SNAREcomplex assembly. The A30P mutation is unique among the $\alpha$-synuclein point mutants in that it did impair SNAREcomplex assembly, possibly due to impaired synaptic targeting (Fig. 3).

\section{Effect of $\alpha$-synuclein mutations on} $\alpha$-synuclein aggregation $\alpha$-Synuclein aggregation into Lewy bodies is a hallmark of PD and other neurodegenerative disorders (Spillantini and Goedert, 2000; Masliah et al., 2001), raising the question how various $\alpha$-synuclein mutations may alter $\alpha$-synuclein aggregation. To assess the aggregation of WT and mutant $\alpha$-synucleins in an intracellular environment, we overexpressed WT and mutant $\alpha$-synucleins in HEK293T cells and measured the amount of protein produced using quantitative immunoblotting (Fig. $7 A, B)$. We then used immunostaining with antibodies to the myc epitope-tag on the expressed $\alpha$-synuclein proteins to quantify the formation of $\alpha$-synuclein aggregates (Fig. $7 C-E)$.

HEK cells were transfected with equal amounts of expression vectors encoding WT and mutant $\alpha$-synucleins. Two days after transfection, expression levels were analyzed by immunoblotting with antibodies against the myc-epitope $(\boldsymbol{A})$ and quantitated as percentage of WT levels $(\boldsymbol{B})$. $\boldsymbol{C}-\boldsymbol{E}$, Aggregation of wild-type and mutant $\alpha$-synucleins in the transfected HEK293T cells. Two days after transfection, cells were fixed and immunostained with antibodies against the myc-epitope $(\boldsymbol{C}, \boldsymbol{D})$. C shows magnified images to highlight differences in aggregation for WT (modest aggregation), 1-95 (highest amount of aggregation), and 42-140 (lowest amount of aggregation) variants of $\alpha$-synuclein. Single-headed arrows mark aggregates. Double-headed arrows indicate areas with no aggregation. Number of immunopositive aggregates per field was quantitated and compared with WT levels $(\boldsymbol{E})$. Data in $\boldsymbol{B}$ and $\boldsymbol{E}$ are means $\pm \operatorname{SEM}\left({ }^{*} p<0.05,{ }^{* *} p<0.01,{ }^{* * *} p<\right.$ 0.001 by Student's $t$ test; $n=5$ independent cultures). 


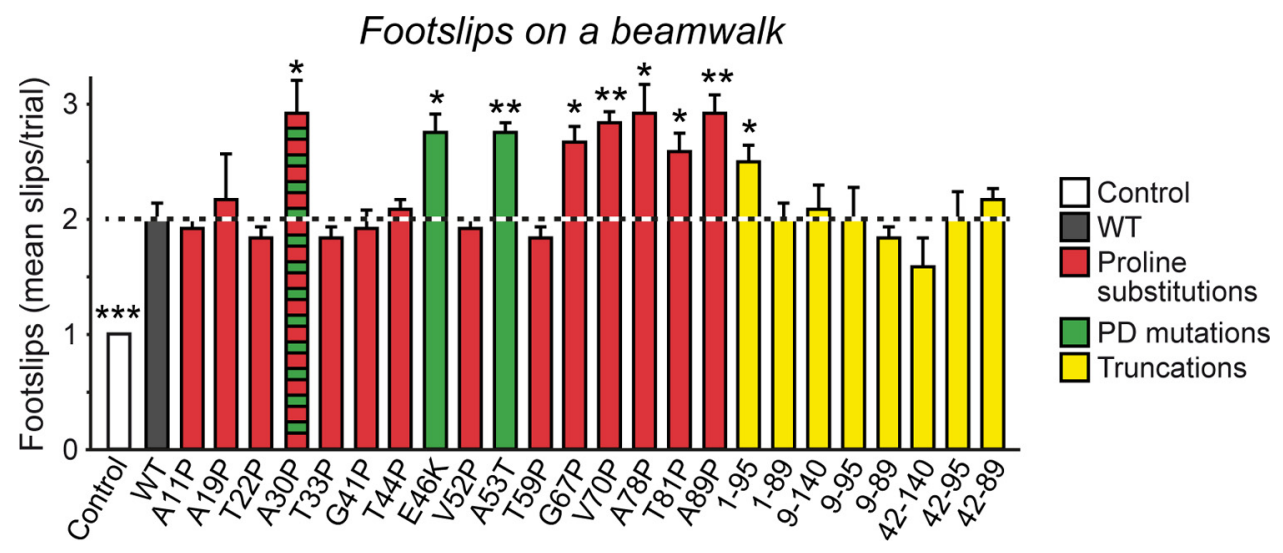

Figure 8. Motor defects in mice injected into the substantia nigra pars compacta with lentiviruses expressing WT and mutant $\alpha$-synucleins. Motor defects were assayed using the beamwalk task in which footslips on a beamwalk are measured. Control lentivirus (Control) or lentiviruses expressing WT or mutant $\alpha$-synucleins were stereotactically and unilaterally injected into the substantia nigra pars compacta of $40-45 \mathrm{~d}$ old mice, and mice were analyzed by three rounds of beamwalks per session $45 \mathrm{~d}$ after injections. Averaged footslips were recorded. Data are means \pm SEM $\left({ }^{*} p<\right.$ $0.05,{ }^{* *} p<0.01$ by Student's $t$ test; $n=4$ mice).

All $\alpha$-synuclein proteins were expressed at similar levels except for the truncations that included only the single $\alpha$-helix (Fig. $7 A, B)$. As expected, all three PD mutations of $\alpha$-synuclein increased the propensity of $\alpha$-synuclein to aggregate (Fig. $7 D, E$ ). Moreover, consistent with previous results (Liu et al., 2005; Lewis et al., 2010), C-terminal truncations enhanced $\alpha$-synuclein aggregation (Fig. $7 C-E$ ). However, most proline substitutions had no effect on $\alpha$-synuclein aggregation except those falling in the so-called "nonamyloid $\beta$ component" (NAC) region, which is consistent with the known involvement of this region in synuclein aggregation (Giasson et al., 2001; Uversky and Fink, 2002; Du et al., 2003; Waxman et al., 2009).

\section{WT and mutant $\alpha$-synucleins impair nigrostriatal function} in vivo

Does either the loss of function of $\alpha$-synuclein, or the aggregation propensity of various $\alpha$-synuclein mutants correlate with their pathological potential in vivo? To monitor the effects of $\alpha$-synuclein mutants on dopaminergic cell survival and mouse motor performance, we stereotactically injected control lentivirus and lentiviruses expressing WT and mutant $\alpha$-synucleins unilaterally into the substantia nigra of WT mice. We performed these injections on postnatal day $40-45$, and monitored motor coordination in the injected mice every $5 \mathrm{~d}$, starting $10 \mathrm{~d}$ after injection.

Beamwalk analysis, used to measure balance and motor function, showed that mice injected with $\alpha$-synuclein lentivirus performed worse than mice injected with control virus (Fig. 8), confirming previous studies that lentiviral overexpression of $\alpha$-synuclein in the substantia nigra produces a dysfunction of motor performance (Lo Bianco et al., 2002; Lauwers et al., 2007; Alerte et al., 2008). A comparison of the effects of various $\alpha$-synuclein mutants with WT $\alpha$-synuclein revealed that exactly those mutations that increased $\alpha$-synuclein aggregation (Fig. 7) also increased the motor impairment upon nigrostriatal expression (Fig. 8). The only difference between the aggregation and motor dysfunction effects of $\alpha$-synuclein mutants was that the deletion of the N-terminal 8 residues did not decrease the increased aggregation of C-terminally truncated $\alpha$-synuclein (Fig. 7), but did prevent the enhancement of motor dysfunction induced by the C-terminal truncation (Fig. 8).

To assess motor function in mice overexpressing mutant $\alpha$-synuclein in the substantia nigra with a second, independent assay, we monitored these mice on a forceplate actometer
(Fowler et al., 2001) (Fig. 9A). Quantitation of the movements of the mice on the forceplate revealed that WT $\alpha$-synuclein overexpression significantly decreased the mobility of the mice as measured by the number of low-mobility bouts and spatial confinement (Fig. 9B). Strikingly, the overall pattern of the effects of the mutations in $\alpha$-synuclein on motor impairment was the same as that observed with the beamwalk assay, although the forceplate assay was notably noisier (Fig. 9). Specifically, the PDassociated mutations, proline substitutions in the NAC region, and C-terminal truncations again enhanced the deleterious effect of overexpressed $\alpha$-synuclein, whereas other mutations had no significant effect on the impairment of motor function by $\alpha$-synuclein. The only difference between the results with the two assays (beamwalk and forceplate) was that the latter also identified a phenotype associated with one of proline substitutions (A19P), and suggested a trend for several other mutations.

\section{$\alpha$-Synuclein induced neuronal cell loss in the substantia nigra}

Do motor impairments in mice with lentiviral expression of various mutants of $\alpha$-synuclein correlate with neuron loss in the injected area? To assess and compare cell loss in the substantia nigra, we killed mice $45 \mathrm{~d}$ after injection, and analyzed dopaminergic cell loss by quantitating TH-positive neurons (Fig. 10). GFP produced by the viruses via an internal ribosomal entry site was used to identify the injection site. Compared with control injections, brains expressing WT or mutant $\alpha$-synucleins exhibited an overall reduction in the number of dopaminergic neurons in the injected area, suggesting that simple overexpression of $\alpha$-synuclein causes death of dopaminergic neurons (Fig. 10A,B). Note that the reduced GFP fluorescence in some brain slices may be caused by loss of infected neurons. We found that $\alpha$-synuclein with PD-associated mutations caused an even larger loss of dopaminergic neurons than WT $\alpha$-synuclein. In addition, the same proline mutations that produced increased $\alpha$-synuclein aggregation (Fig. 7) and impaired motor function in the injected mice (Figs. 8, 9) also enhanced the neurotoxic effect of $\alpha$-synuclein (Fig. 10). The effect of truncated $\alpha$-synuclein, however, was less strong, although even here significant enhancement of the deleterious effects of $\alpha$-synuclein was observed.

Next, we asked whether $\alpha$-synuclein overexpression also affects nondopaminergic neurons in the injected area. Since neurons labeled by NeuN antibodies do not coincide with $\mathrm{TH}$ expressing neurons (Cannon and Greenamyre, 2009), we assessed the loss of NeuN-positive neurons by measuring the 
A
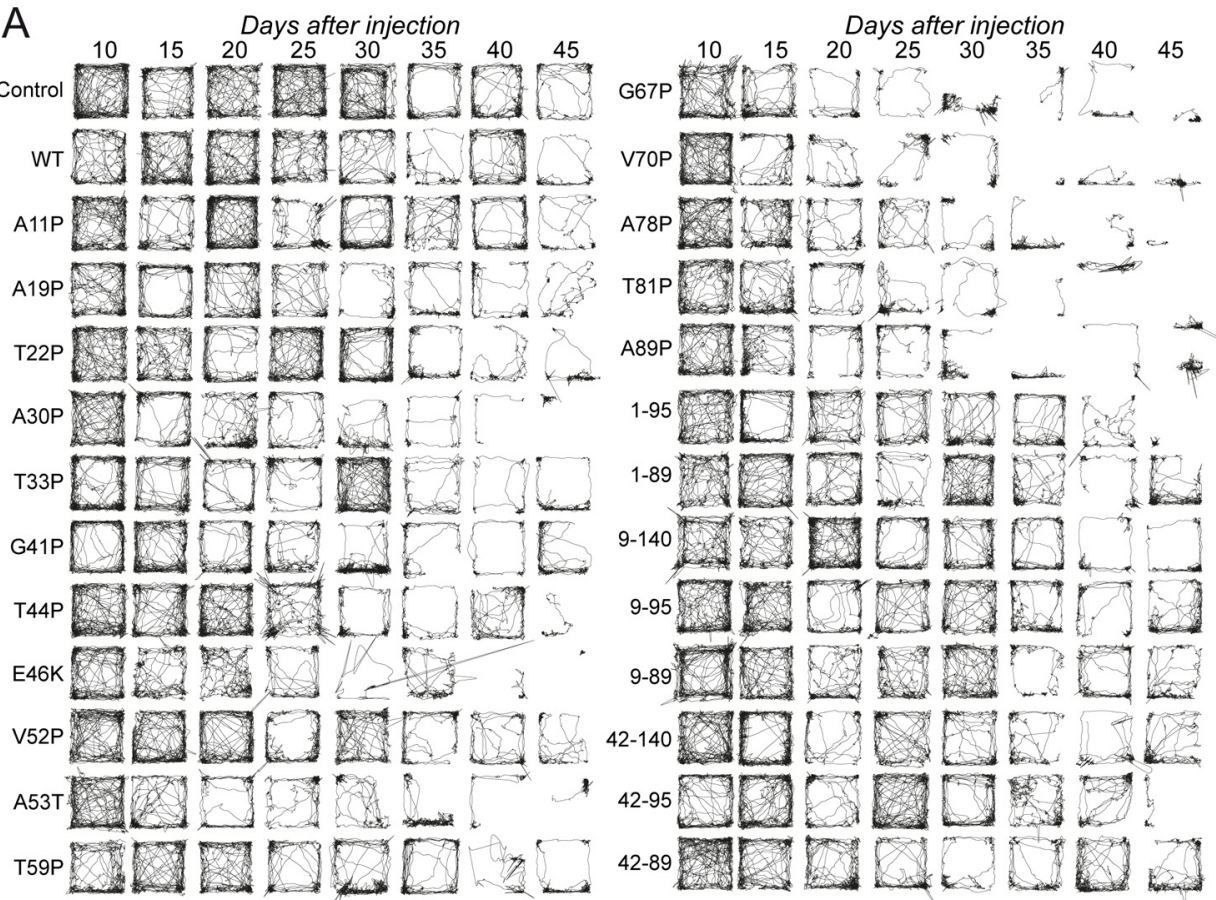

B
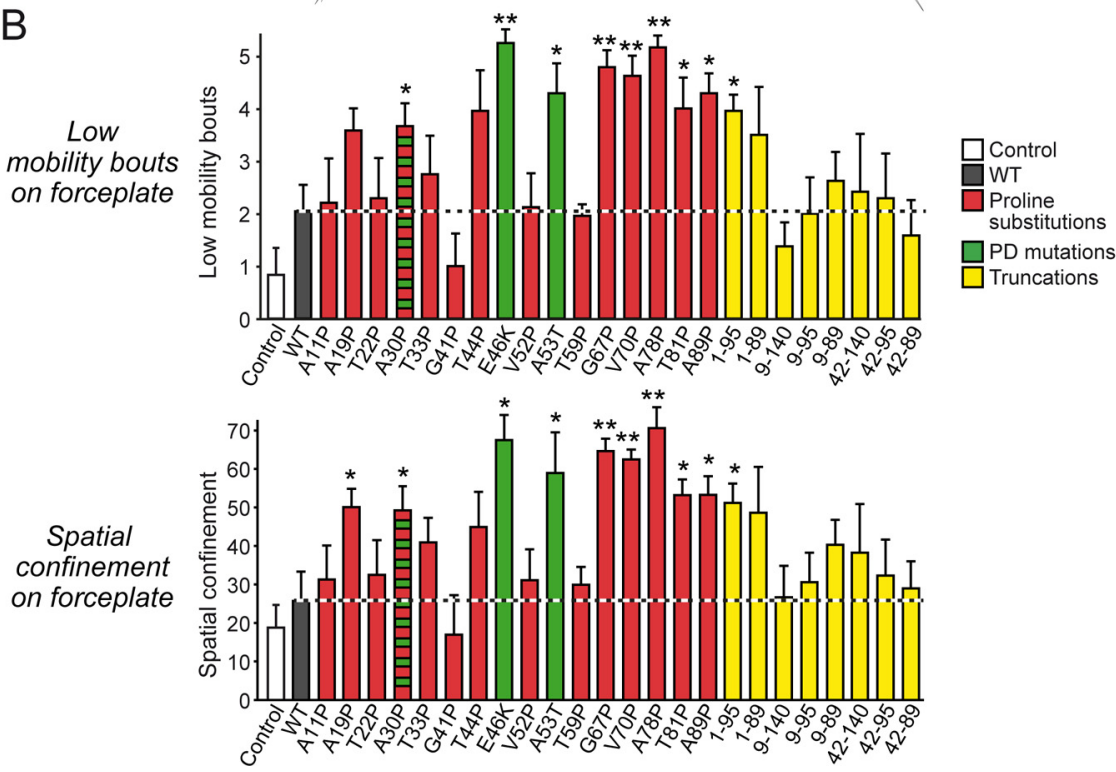

Figure 9. Forceplate analysis of motor function in mice injected into the substantia nigra with lentiviruses expressing WT and mutant $\alpha$-synuclein. $A$, Representative traces of forceplate analyses. WT mice $40-45 \mathrm{~d}$ old were injected as described for Figure 8 , and were monitored every $5 \mathrm{~d}$, starting $10 \mathrm{~d}$ after injection until $45 \mathrm{~d}$ after injection, when mice were examined by the beamwalk task (Fig. 8) and killed for histochemical analysis. B, Analysis of low-mobility bouts (top) and spatial confinement (bottom), as calculated from the forceplate data obtained with multiple identically injected mice. Data were plotted as the difference between day 45 and day 10 after injection. Data are means \pm SEM ( ${ }^{*} p<0.05,{ }^{* *} p<0.01$ by Student's $t$ test; $n=4$ mice).

NeuN/DAPI ratio (Fig. 10) (Sharma et al., 2011b). We found a reduction of neuron numbers for WT $\alpha$-synuclein injections compared with control injections. Moreover, we observed a significantly greater reduction of neuron number for PD and NACdomain mutants and the C-terminally truncated $\alpha$-synuclein ${ }^{1-95}$ than for WT $\alpha$-synuclein. These data suggest that overexpression of $\alpha$-synuclein does not specifically induce cell death only in dopaminergic neurons, but is toxic to neurons in general.

Overall, all pathological readouts correlate well with each other in that $\mathrm{PD}$-associated mutations and point mutations in the NAC region as well as C-terminal truncations of $\alpha$-synuclein increase $\alpha$-synuclein aggregation and pathology compared with WT $\alpha$-synuclein. Our data further demon- strate that loss of function of $\alpha$-synuclein does not correlate with increased aggregation propensity/pathology, suggesting that pathology in synucleinopathies may arise from a gain-oftoxic function of $\alpha$-synuclein.

\section{Discussion}

Although extensive evidence established a central role for $\alpha$-synuclein in the pathogenesis of neurodegenerative disorders, especially PD (Spillantini and Goedert, 2000; Masliah et al., 2001; Dawson and Dawson, 2003), the structure-function relations of $\alpha$-synuclein in neurodegeneration remain unknown. Previous studies examining how $\alpha$-synuclein acts in neurodegeneration have rarely correlated in vitro and in vivo 

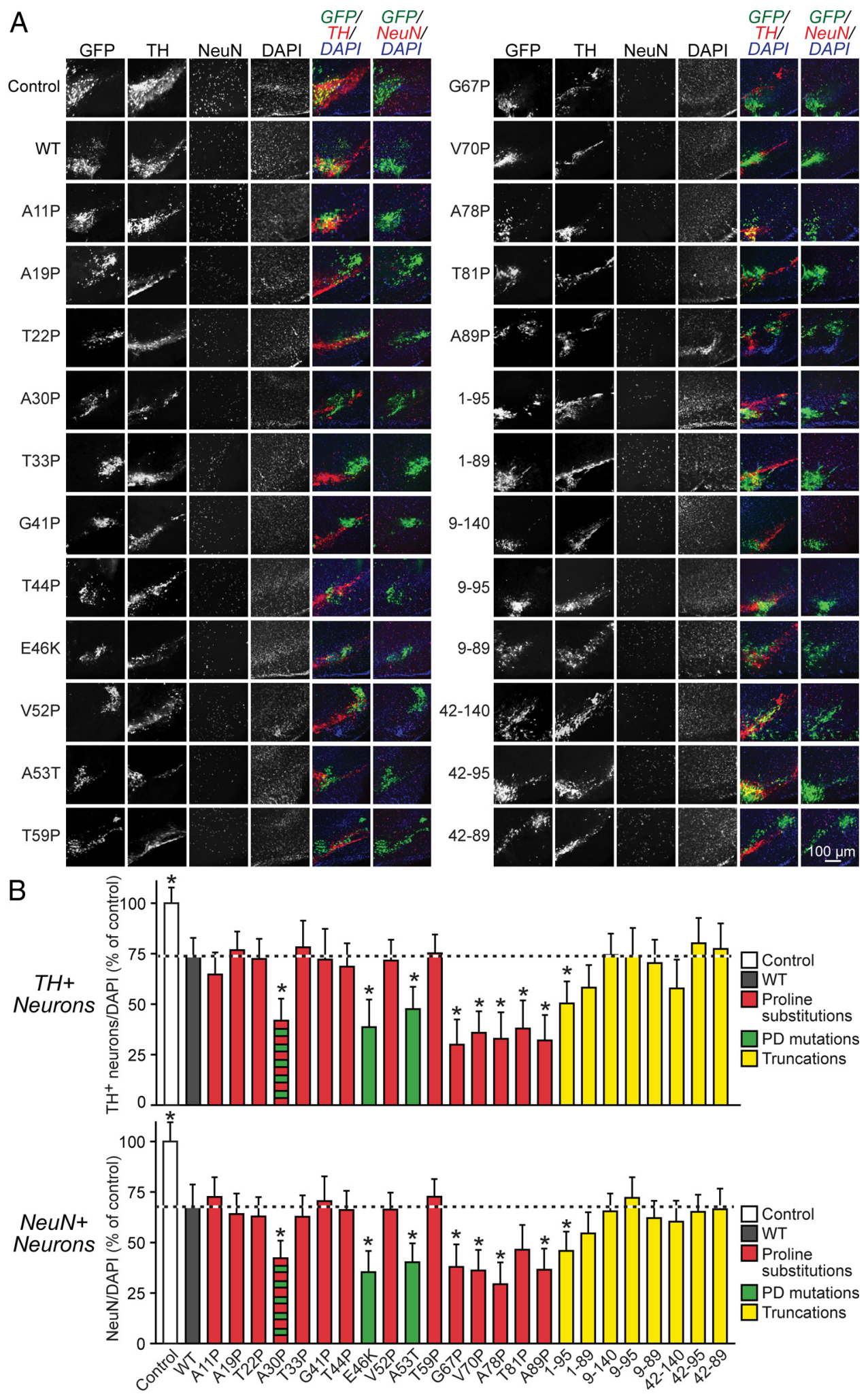

Figure 10. Neuron loss in mice expressing $\alpha$-synuclein mutants in the substantia nigra. A, Control lentiviruses (control) or lentiviruses expressing WT or mutant $\alpha$-synucleins were stereotactically and unilaterally injected into the substantia nigra of $40-45-\mathrm{d}$-old mice. Forty-five days after injection, injected areas were immunostained for either TH (red) or NeuN (red), and DAPI (blue). IRES-driven GFP marks the injection site. $\boldsymbol{B}$, The density of dopaminergic neurons was quantitated by immunostaining for TH (top), and the density of NeuN-positive (nondopaminergic) neurons was quantitated by immunostaining for NeuN (bottom). Data are means \pm SEM $\left({ }^{*} p<0.05,{ }^{* *} p<0.01\right.$ by Student's $t$ test; $n=4$ mice).

activities of $\alpha$-synuclein mutants, and no systematic mutagenesis of the entire molecule was previously performed. Perhaps the most important unaddressed issue, however, is whether the neuropathological effects of $\alpha$-synuclein are related to its physiological functions. This issue is particularly pertinent because the physiological role of $\alpha$-synuclein as a SNARE chaperone can, at least in the context of the neurodegeneration caused by deletion of $\operatorname{CSP} \alpha$, act to prevent neurodegeneration (Chandra 
$\alpha-S y n u c l e i n$
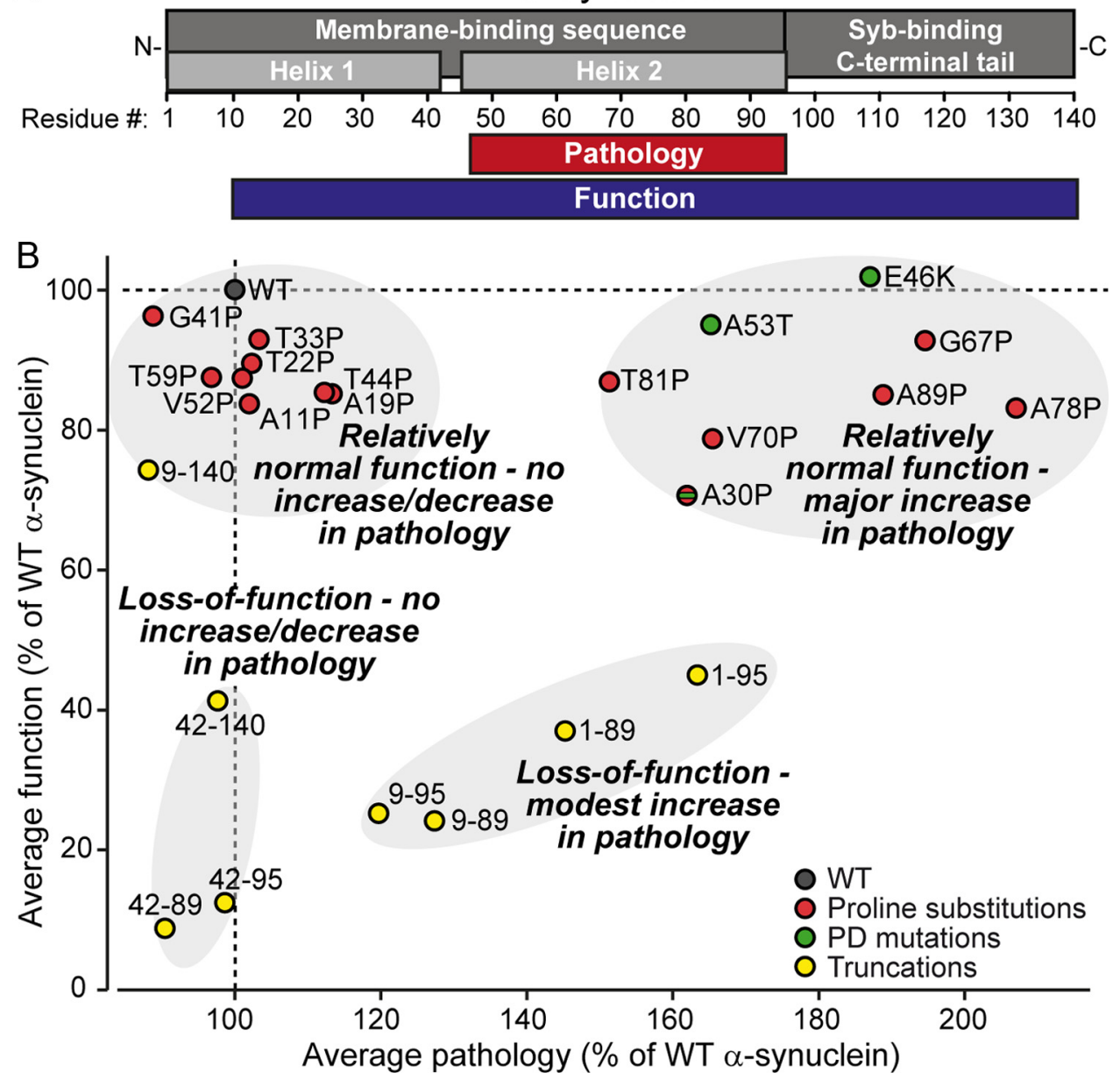

Figure 11. Summary of the effects of $\alpha$-synuclein mutations on the function and neurotoxic activity of $\alpha$-synuclein. $\boldsymbol{A}, \alpha$-Synuclein domain structure (top) and delineation of $\alpha$-synuclein regions (bottom) that mediate the neurotoxic effects (red) and physiological SNARE-complex assembly function of $\alpha$-synuclein (blue). $\boldsymbol{B}$, Plot of the effects of alpha-synuclein mutations on the function and neurotoxic activity of $\alpha$-synuclein, normalized to the activity of WT $\alpha$-synuclein. Averaged function was calculated from the data for lipid binding, synaptic targeting, synaptobrevin- 2 binding, and SNARE-complex stabilization (Figs. 2-6). Averaged pathology was obtained from the data for $\alpha$-synuclein aggregation in HEK cells, footslips on a beamwalk, forceplate analysis, loss of dopaminergic neurons, and loss of total neurons (Figs. 7-10). See Materials and Methods for details.

et al., 2005), thus raising the question whether the neuropathological effects of $\alpha$-synuclein are possibly caused by a loss of $\alpha$-synuclein function. The present study attempts to address these issues in a systematic analysis of $26 \alpha$-synuclein mutants using seven assays for its physiological and pathological actions. The relative effects of the $\alpha$-synuclein mutations on the physiological and pathological actions of $\alpha$-synuclein are summarized in Figure 11. Overall, our data suggest the following conclusions:

1. There is no correlation between the sequences required for physiological and pathological actions of $\alpha$-synuclein. Functionally inactive $\alpha$-synuclein does not necessarily produce pathology, whereas many mutations that enhance the neuropathogenic effect of $\alpha$-synuclein do not detectably alter its physiological function as a SNARE chaperone.

2. Full phospholipid binding is not required for the physiological function of $\alpha$-synuclein as a SNARE chaperone at the synapse. Only when $>75 \%$ of lipid binding is reduced (e.g., helix 1 is missing), is the physiological function of $\alpha$-synuclein impaired.

3. Synaptic targeting of $\alpha$-synuclein is mediated by both lipid and synaptobrevin-2 binding.

4. The two $\alpha$-helices and the C-terminal region of $\alpha$-synuclein are both essential for its function as a SNARE-chaperone, the former probably because they bind to phospholipids and the latter probably because it binds to synaptobrevin-2.

5. The propensity of $\alpha$-synuclein to aggregate and the pathogenic effects of $\alpha$-synuclein are independent of its $\mathrm{N}$-terminal $\alpha$-helix, but enhanced by point mutations in its central $\alpha$-helix and by deletion of its C-terminal region. Thus, the aggregation and neurotoxicity of $\alpha$-synuclein correlate precisely, suggesting that the two processes are related.

Overall, our data support the notion that aggregation of $\alpha$-synuclein is a central element of its neurotoxicity, extending results from previous studies showing that PD mutants of $\alpha$-synuclein increase the propensity of protofibril or fibril formation of $\alpha$-synuclein (Narhi et al., 1999; Conway et al., 2000; Greenbaum et al., 2005; Ono et al., 2011) and thus pathology in familial PD cases (Polymeropoulos et al., 1997; Krüger et al., 1998; Zarranz et al., 2004). Mechanistically, $\alpha$-synuclein aggregation could cause neurotoxicity via at least two pathways. Aggregation of $\alpha$-synuclein could be in itself neurotoxic. The resulting aggregates could damage neurons either as oligomers or as inclusion bodies, thereby impairing neuronal viability (Spillantini and Goedert, 2000; Masliah et al., 2001; Kayed et al., 2003; Volles and Lansbury, 2003; Lindersson et al., 
2004; Lansbury and Lashuel, 2006; Tsika et al., 2010; Colla et al., 2012). Alternatively, $\alpha$-synuclein aggregates could serve to nucleate aggregation of all cellular synucleins, thereby depleting the neuron of synucleins and causing an indirect loss-of-function effect. Although we cannot at present completely rule out the second hypothesis, several lines of evidence argue against it. Possibly the most compelling argument against the indirect loss-of-function hypothesis is the observation that a complete loss of all synucleins in triple $\alpha / \beta / \gamma$ synuclein $\mathrm{KO}$ mice does not lead to the same major neuropathology as the overexpression of mutant $\alpha$-synuclein. Specifically, synucleindeficient mice display motor impairments only after $200 \mathrm{~d}$ and have no neuronal loss (Burré et al., 2010), suggesting that the loss-offunction phenotype of $\alpha$-synuclein is a process different from the observed neuropathology.

In agreement with the PD pathology observed in humans (Singleton et al., 2003; Ibáñez et al., 2004), we found that increased expression of WT $\alpha$-synuclein is sufficient to cause pathology. All three PD mutants aggravated the $\alpha$-synuclein pathology in our assays. We found that the pathology induced by lentiviral expression of $\alpha$-synuclein in the substantia nigra manifests not only as the loss of dopaminergic neurons but also as a loss of other neurons in the injected area. While loss of dopaminergic neurons in the substantia nigra is responsible for motor symptoms in PD (Fahn and Sulzer, 2004), a variety of other neurons in the central and peripheral nervous system also exhibit signs of pathology in postmortem analysis, suggesting that pathology induced by $\alpha$-synuclein is not limited to dopaminergic neurons (Braak et al., 2007; Baba et al., 2012; Sulzer and Surmeier, 2012).

Importantly we found that mutations in the NAC region of $\alpha$-synuclein cause pathology in mice similar to familial PD mutations. NAC was originally isolated as a component of $\beta$-amyloid from brain tissue of Alzheimer's patients (Uéda et al., 1993 ), and was later identified as a fragment of $\alpha$-synuclein (Nakajo et al., 1993; Jakes et al., 1994). The NAC region comprises residues $61-95$ of $\alpha$-synuclein, a region that is thought to drive fibril formation (Giasson et al., 2001; Uversky and Fink, 2002; Du et al., 2003; Waxman et al., 2009). Indeed, all of our mutants falling into this region (G67P, V70P, A78P, T81P, A89P) consistently increased the aggregation and pathogenicity of $\alpha$ synuclein. Introduction of proline residues into the already aggregation-prone NAC region is predicted to reduce its helical content, and may thus shift the conformational equilibrium of $\alpha$-synuclein further toward $\beta$-sheet content and subsequently toward more fibril formation, resulting in increased pathology. It is interesting that the $\mathrm{N}$-terminal $\alpha$-helix of $\alpha$-synuclein (Chandra et al., 2005) binds more tightly to lipids than the C-terminal $\alpha$-helix (which coincides with the NAC region) (Drescher et al., 2008), which may account for the greater aggregation propensity of the C-terminal $\alpha$-helix containing the NAC region. Overall, our data suggest that, if familial mutations within the NAC domain were to be found in PD patients, they would cause similarly or more severe phenotypes than those reported for known familial mutations.

C-terminally truncated $\alpha$-synuclein is enriched in human Lewy body extracts (Baba et al., 1998; Tofaris et al., 2003). Abnormal neurites containing C-terminally truncated $\alpha$-synuclein are present in Alzheimer's disease without conventional Lewy body pathology (Lewis et al., 2010), and transgenic mice expressing C-terminally truncated forms of human $\alpha$-synuclein develop PD-like symptoms and exhibit PD-like neuronal pathology (Tofaris et al., 2006; Wakamatsu et al., 2008). Furthermore, coexpression of C-terminal truncated $\alpha$-synuclein enhances fulllength $\alpha$-synuclein-induced pathology (Liu et al., 2005; Ulusoy et al., 2010). The charge in the unstructured $C$ terminus exerts a profound effect on the aggregation rate of $\alpha$-synuclein (Hoyer et al., 2004; Levitan et al., 2011), and it has been suggested that interaction between the C-terminal and N-terminal or central NAC region are important in maintaining the natively unfolded structure of $\alpha$-synuclein and in preventing $\alpha$-synuclein from changing conformation (Hong et al., 2011). Thus, removal of the $\mathrm{C}$ terminus may increase aggregation rate and account for the observed pathology in our assays.

In our assays, all proline mutants we analyzed bind to synaptobrevin-2 and reveal similar impairment in lipid binding. However, only the A30P mutation demonstrated decreased synaptic targeting and thus less SNARE-complex stabilization. This result is puzzling, since mutation of the corresponding residues within other 11-mer repeats did not result in a similar loss of function or aggregation of $\alpha$-synuclein. What makes A30P so special? We cannot exclude the possibility that under physiological conditions lipid binding may be influenced by other factors. Alanine $^{30}$ may be crucial for proper helix formation of $\alpha$-synuclein. For A30P, loss of helicity upstream and downstream of the substitution has been suggested (Bussell and Eliezer, 2004; Ulmer and Bax, 2005), and disruption of helicity in A30P may be more severe than for other proline mutants. Whatever mechanism turns out to be responsible for the increased cytosolic localization of A30P, this increased cytosolic localization compared with other proline mutations within the first $\alpha$-helix of $\alpha$-synuclein may account for the increased pathology: shifting of $\alpha$-synuclein structure toward a more unfolded state may allow increased $\beta$-sheet formation and aggregation, and thus increased pathology.

Truncation of the N-terminal 8 residues of $\alpha$-synuclein resulted in a $60 \%$ decrease in lipid binding. These eight residues are part of the first $\alpha$-helix of $\alpha$-synuclein (Chandra et al., 2003), but precede its first 11-residue repeat. Surprisingly, deletion of this short helical stretch thus may affect helical structure more severely than introduction of single proline residues within the helix, which disturb protein folding only locally, as shown for A30P (Bussell and Eliezer, 2004; Ulmer and Bax, 2005). Similarly, most proline mutants resulted in comparable impairments in lipid binding except for G41P, which did not affect binding of $\alpha$-synuclein to liposomes. Likely, introduction of a helix-breaking proline residue at the very end of helix 1 has less impact on helicity than proline residues in the middle of a helical domain.

In summary, our data suggest that $\alpha$-synuclein pathology is not caused by loss of function of $\alpha$-synuclein, but by gain of toxic function. Since single $\alpha$-synuclein KO mice do not show significant neuropathology (Abeliovich et al., 2000; Schluter et al., 2003), and knock-out of all three synuclein genes causes significant pathology only in older mice (Burré et al., 2010; GretenHarrison et al., 2010; Anwar et al., 2011), suppression of $\alpha$-synuclein expression alone may not be pathogenic in humans. Therapies to reduce or abolish $\alpha$-synuclein expression may thus be a worthwhile strategy to decrease or prevent $\alpha$-synucleininduced pathology.

\section{References}

Abeliovich A, Schmitz Y, Fariñas I, Choi-Lundberg D, Ho WH, Castillo PE, Shinsky N, Verdugo JM, Armanini M, Ryan A, Hynes M, Phillips H, Sulzer D, Rosenthal A (2000) Mice lacking alpha-synuclein display functional deficits in the nigrostriatal dopamine system. Neuron 25:239252.

Alerte TN, Akinfolarin AA, Friedrich EE, Mader SA, Hong CS, Perez RG (2008) Alpha-synuclein aggregation alters tyrosine hydroxylase phos- 
phorylation and immunoreactivity: lessons from viral transduction of knock-out mice. Neurosci Lett 435:24-29.

Anderson JP, Walker DE, Goldstein JM, de Laat R, Banducci K, Caccavello RJ, Barbour R, Huang J, Kling K, Lee M, Diep L, Keim PS, Shen X, Chataway T, Schlossmacher MG, Seubert P, Schenk D, Sinha S, Gai WP, Chilcote TJ (2006) Phosphorylation of Ser-129 is the dominant pathological modification of alpha-synuclein in familial and sporadic Lewy body disease. J Biol Chem 281:29739-29752.

Anwar S, Peters O, Millership S, Ninkina N, Doig N, Connor-Robson N, Threlfell S, Kooner G, Deacon RM, Bannerman DM, Bolam JP, Chandra SS, Cragg SJ, Wade-Martins R, Buchman VL (2011) Functional alterations to the nigrostriatal system in mice lacking all three members of the synuclein family. J Neurosci 31:7264-7274.

Baba M, Nakajo S, Tu PH, Tomita T, Nakaya K, Lee VM, Trojanowski JQ, Iwatsubo T (1998) Aggregation of alpha-synuclein in Lewy bodies of sporadic Parkinson's disease and dementia with Lewy bodies. Am J Pathol 152:879-884.

Baba T, Kikuchi A, Hirayama K, Nishio Y, Hosokai Y, Kanno S, Hasegawa T, Sugeno N, Konno M, Suzuki K, Takahashi S, Fukuda H, Aoki M, Itoyama Y, Mori E, Takeda A (2012) Severe olfactory dysfunction is a prodromal symptom of dementia associated with Parkinson's disease: a 3 year longitudinal study. Brain 135:161-169.

Beyer K (2006) Alpha-synuclein structure, posttranslational modification and alternative splicing as aggregation enhancers. Acta Neuropathol 112: $237-251$.

Bisaglia M, Tessari I, Pinato L, Bellanda M, Giraudo S, Fasano M, Bergantino E, Bubacco L, Mammi S (2005) A topological model of the interaction between alpha-synuclein and sodium dodecyl sulfate micelles. Biochemistry 44:329-339.

Borbat P, Ramlall TF, Freed JH, Eliezer D (2006) Inter-helix distances in lysophospholipid micelle-bound alpha-synuclein from pulsed ESR measurements. J Am Chem Soc 128:10004-10005.

Bortolus M, Tombolato F, Tessari I, Bisaglia M, Mammi S, Bubacco L, Ferrarini A, Maniero AL (2008) Broken helix in vesicle and micelle-bound alpha-synuclein: insights from site-directed spin labeling-EPR experiments and MD simulation. J Am Chem Soc 130:6690-6691.

Braak H, Sastre M, Del Tredici K (2007) Development of alpha-synuclein immunoreactive astrocytes in the forebrain parallels stages of intraneuronal pathology in sporadic Parkinson's disease. Acta Neuropathol 114: 231-241.

Burré J, Sharma M, Tsetsenis T, Buchman V, Etherton MR, Südhof TC (2010) Alpha-synuclein promotes SNARE-complex assembly in vivo and in vitro. Science 329:1663-1667.

Bussell R Jr, Eliezer D (2004) Effects of Parkinson's disease-linked mutations on the structure of lipid-associated alpha-synuclein. Biochemistry 43:4810-4818.

Cannon JR, Greenamyre JT (2009) NeuN is not a reliable marker of dopamine neurons in rat substantia nigra. Neurosci Lett 464:14-17.

Chandra S, Chen X, Rizo J, Jahn R, Südhof TC (2003) A broken alpha-helix in folded alpha-synuclein. J Biol Chem 278:15313-15318.

Chandra S, Gallardo G, Fernández-Chacón R, Schlüter OM, Südhof TC (2005) Alpha-synuclein cooperates with CSPalpha in preventing neurodegeneration. Cell 123:383-396.

Colla E, Jensen PH, Pletnikova O, Troncoso JC, Glabe C, Lee MK (2012) Accumulation of toxic $\alpha$-synuclein oligomer within endoplasmic reticulum occurs in $\alpha$-synucleinopathy in vivo. J Neurosci 32:3301-3305.

Conway KA, Harper JD, Lansbury PT (1998) Accelerated in vitro fibril formation by a mutant alpha-synuclein linked to early-onset Parkinson disease. Nat Med 4:1318-1320.

Conway KA, Lee SJ, Rochet JC, Ding TT, Harper JD, Williamson RE, Lansbury PT Jr (2000) Accelerated oligomerization by Parkinson's disease linked alpha-synuclein mutants. Ann N Y Acad Sci 920:42-45.

Dawson TM, Dawson VL (2003) Molecular pathways of neurodegeneration in Parkinson's disease. Science 302:819-822.

Drescher M, Godschalk F, Veldhuis G, van Rooijen BD, Subramaniam V, Huber M (2008) Spin-label EPR on alpha-synuclein reveals differences in the membrane binding affinity of the two antiparallel helices. Chembiochem 13:2411-2416.

Du HN, Tang L, Luo XY, Li HT, Hu J, Zhou JW, Hu HY (2003) A peptide motif consisting of glycine, alanine, and valine is required for the fibrillization and cytotoxicity of human alpha-synuclein. Biochemistry 42: $8870-8878$
Fahn S, Sulzer D (2004) Neurodegeneration and neuroprotection in Parkinson disease. NeuroRx 1:139-154.

Fowler SC, Birkestrand BR, Chen R, Moss SJ, Vorontsova E, Wang G, Zarcone TJ (2001) A force-plate actometer for quantitating rodent behaviors: illustrative data on locomotion, rotation, spatial patterning, stereotypies, and tremor. J Neurosci Methods 107:107-124.

Fredenburg RA, Rospigliosi C, Meray RK, Kessler JC, Lashuel HA, Eliezer D, Lansbury PT Jr (2007) The impact of the E46K mutation on the properties of alpha-synuclein in its monomeric and oligomeric states. Biochemistry 46:7107-7118.

Fujiwara H, Hasegawa M, Dohmae N, Kawashima A, Masliah E, Goldberg MS, Shen J, Takio K, Iwatsubo T (2002) Alpha-synuclein is phosphorylated in synucleinopathy lesions. Nat Cell Biol 4:160-164.

Georgieva ER, Ramlall TF, Borbat PP, Freed JH, Eliezer D (2010) The lipidbinding domain of wild type and mutant alpha-synuclein: compactness and interconversion between the broken and extended helix forms. J Biol Chem 285:28261-28274.

Giasson BI, Murray IV, Trojanowski JQ, Lee VM (2001) A hydrophobic stretch of 12 amino acid residues in the middle of alpha-synuclein is essential for filament assembly. J Biol Chem 276:2380-2386.

Greenbaum EA, Graves CL, Mishizen-Eberz AJ, Lupoli MA, Lynch DR, Englander SW, Axelsen PH, Giasson BI (2005) The E46K mutation in alphasynuclein increases amyloid fibril formation. J Biol Chem 280:7800-7807.

Greten-Harrison B, Polydoro M, Morimoto-Tomita M, Diao L, Williams AM, Nie EH, Makani S, Tian N, Castillo PE, Buchman VL, Chandra SS (2010) $\alpha \beta \gamma$-Synuclein triple knockout mice reveal age-dependent neuronal dysfunction. Proc Natl Acad Sci U S A 107:19573-19578.

Hayashi T, McMahon H, Yamasaki S, Binz T, Hata Y, Südhof TC, Niemann H (1994) Synaptic vesicle membrane fusion complex: action of clostridial neurotoxins on assembly. EMBO J 13:5051-5061.

Hong DP, Xiong W, Chang JY, Jiang C (2011) The role of the C-terminus of human alpha-synuclein: intra-disulfide bonds between the C-terminus and other regions stabilize non-fibrillar monomeric isomers. FEBS Lett 585:561-566.

Hoyer W, Cherny D, Subramaniam V, Jovin TM (2004) Impact of the acidic C-terminal region comprising amino acids $109-140$ on alpha-synuclein aggregation in vitro. Biochemistry 43:16233-16242.

Ibáñez P, Bonnet AM, Debarges B, Lohmann E, Tison F, Pollak P, Agid Y, Dürr A, Brice A (2004) Causal relation between alpha-synuclein gene duplication and familial Parkinson's disease. Lancet 364:1169-1171.

Iwai A, Masliah E, Yoshimoto M, Ge N, Flanagan L, de Silva HA, Kittel A, Saitoh T (1995) The precursor protein of non-A beta component of Alzheimer's disease amyloid is a presynaptic protein of the central nervous system. Neuron 14:467-475.

Jakes R, Spillantini MG, Goedert M (1994) Identification of two distinct synucleins from human brain. FEBS Lett 345:27-32.

Kahle PJ, Neumann M, Ozmen L, Muller V, Jacobsen H, Spooren W, Fuss B, Mallon B, Macklin WB, Fujiwara H, Hasegawa M, Iwatsubo T, Kretzschmar HA, Haass C (2002) Hyperphosphorylation and insolubility of alpha-synuclein in transgenic mouse oligodendrocytes. EMBO Rep 3:583-588.

Kayed R, Head E, Thompson JL, McIntire TM, Milton SC, Cotman CW, Glabe CG (2003) Common structure of soluble amyloid oligomers implies common mechanism of pathogenesis. Science 300:486-489.

Krüger R, Kuhn W, Müller T, Woitalla D, Graeber M, Kösel S, Przuntek H, Epplen JT, Schöls L, Riess O (1998) Ala30Pro mutation in the gene encoding alpha-synuclein in Parkinson's disease. Nat Genet 18:106-108.

Lansbury PT, Lashuel HA (2006) A century-old debate on protein aggregation and neurodegeneration enters the clinic. Nature 443:774-779.

Lauwers E, Bequ é D, Van Laere K, Nuyts J, Bormans G, Mortelmans L, Casteels C, Vercammen L, Bockstael O, Nuttin B, Debyser Z, Baekelandt $\mathrm{V}$ (2007) Non-invasive imaging of neuropathology in a rat model of alpha-synuclein overexpression. Neurobiol Aging 28:248-257.

Levitan K, Chereau D, Cohen SI, Knowles TP, Dobson CM, Fink AL, Anderson JP, Goldstein JM, Millhauser GL (2011) Conserved C-terminal charge exerts a profound influence on the aggregation rate of alphasynuclein. J Mol Biol 411:329-333.

Lewis KA, Su Y, Jou O, Ritchie C, Foong C, Hynan LS, White CL 3rd, Thomas PJ, Hatanpaa KJ (2010) Abnormal neurites containing C-terminally truncated alpha-synuclein are present in Alzheimer's disease without conventional Lewy body pathology. Am J Pathol 177:3037-3050.

Lindersson E, Beedholm R, Højrup P, Moos T, Gai W, Hendil KB, Jensen PH 
(2004) Proteasomal inhibition by alpha-synuclein filaments and oligomers. J Biol Chem 279:12924-12934.

Liu CW, Giasson BI, Lewis KA, Lee VM, Demartino GN, Thomas PJ (2005) A precipitating role for truncated alpha-synuclein and the proteasome in alpha-synuclein aggregation: implications for pathogenesis of Parkinson disease. J Biol Chem 280:22670-22678.

Lo Bianco C, Ridet JL, Schneider BL, Deglon N, Aebischer P (2002) $\alpha$-Synucleinopathy and selective dopaminergic neuron loss in a rat lentiviral-based model of Parkinson's disease. Proc Natl Acad Sci U S A 99:10813-10818.

Lokappa SB, Ulmer TS (2011) Alpha-synuclein populates both elongated and broken helix states on small unilamellar vesicles. J Biol Chem 286:21450-21457.

Maroteaux L, Campanelli JT, Scheller RH (1988) Synuclein: a neuronspecific protein localized to the nucleus and presynaptic nerve terminal. J Neurosci 8:2804-2815.

Masliah E, Rockenstein E, Veinbergs I, Sagara Y, Mallory M, Hashimoto M, Mucke L (2001) beta-amyloid peptides enhance alpha-synuclein accumulation and neuronal deficits in a transgenic mouse model linking Alzheimer's disease and Parkinson's disease. Proc Natl Acad Sci U S A 98:12245-12250.

Maximov A, Pang ZP, Tervo DG, Südhof TC (2007) Monitoring synaptic transmission in primary neuronal cultures using local extracellular stimulation. J Neurosci Methods 161:75-87.

McFarland MA, Ellis CE, Markey SP, Nussbaum RL (2008) Proteomics analysis identifies phosphorylation-dependent alpha-synuclein protein interactions. Mol Cell Proteomics 7:2123-2137.

Nakajo S, Tsukada K, Omata K, Nakamura Y, Nakaya K (1993) A new brainspecific $14-\mathrm{kDa}$ protein is a phosphoprotein. Its complete amino acid sequence and evidence for phosphorylation. Eur J Biochem 217:1057-1063.

Narhi L, Wood SJ, Steavenson S, Jiang Y, Wu GM, Anafi D, Kaufman SA, Martin F, Sitney K, Denis P, Louis JC, Wypych J, Biere AL, Citron M (1999) Both familial Parkinson's disease mutations accelerate alphasynuclein aggregation. J Biol Chem 274:9843-9846.

Okochi M, Walter J, Koyama A, Nakajo S, Baba M, Iwatsubo T, Meijer L, Kahle PJ, Haass C (2000) Constitutive phosphorylation of the Parkinson's disease associated alpha-synuclein. J Biol Chem 275:390-397.

Ono K, Ikeda T, Takasaki J, Yamada M (2011) Familial Parkinson disease mutations influence alpha-synuclein assembly. Neurobiol Dis 43:715-724.

Paleologou KE, Schmid AW, Rospigliosi CC, Kim HY, Lamberto GR, Fredenburg RA, Lansbury PT Jr, Fernandez CO, Eliezer D, Zweckstetter M, Lashuel HA (2008) Phosphorylation at Ser-129 but not the phosphomimics S129E/D inhibits the fibrillation of alpha-synuclein. J Biol Chem 283:16895-16905.

Paleologou KE, Oueslati A, Shakked G, Rospigliosi CC, Kim HY, Lamberto GR, Fernandez CO, Schmid A, Chegini F, Gai WP, Chiappe D, Moniatte M, Schneider BL, Aebischer P, Eliezer D, Zweckstetter M, Masliah E, Lashuel HA (2010) Phosphorylation at S87 is enhanced in synucleinopathies, inhibits $\alpha$-synuclein oligomerization, and influences synuclein-membrane interactions. J Neurosci 30:3184-3198.

Perrin RJ, Woods WS, Clayton DF, George JM (2000) Interaction of human alpha-Synuclein and Parkinson's disease variants with phospholipids. Structural analysis using site-directed mutagenesis. J Biol Chem 275:34393-34398.

Polymeropoulos MH, Lavedan C, Leroy E, Ide SE, Dehejia A, Dutra A, Pike B, Root H, Rubenstein J, Boyer R, Stenroos ES, Chandrasekharappa S, Athanassiadou A, Papapetropoulos T, Johnson WG, Lazzarini AM, Duvoisin RC, Di Iorio G, Golbe LI, Nussbaum RL (1997) Mutation in the alphasynuclein gene identified in families with Parkinson's disease. Science 276:2045-2047.

Rosahl TW, Spillane D, Missler M, Herz J, Selig DK, Wolff JR, Hammer RE, Malenka RC, Südhof TC (1995) Essential functions of synapsins I and II in synaptic vesicle regulation. Nature 375:488-493.

Schluter OM, Fornai F, Alessandr í MG, Takamori S, Geppert M, Jahn R, Südhof TC (2003) Role of alpha-synuclein in 1-methyl-4-phenyl1,2,3,6-tetrahydropyridine-induced parkinsonism in mice. Neuroscience 118:985-1002.

Schoch S, Deák F, Königstorfer A, Mozhayeva M, Sara Y, Südhof TC, Kavalali ET (2001) SNARE function analyzed in synaptobrevin/VAMP knockout mice. Science 294:1117-1122.

Sharma M, Burré J, Südhof TC (2011a) CSPalpha promotes SNAREcomplex assembly by chaperoning SNAP-25 during synaptic activity. Nat Cell Biol 13:30-39.
Sharma M, Burr é J, Bronk P, Zhang Y, Xu W, Südhof TC (2011b) CSP $\alpha$ knockout causes neurodegeneration by impairing SNAP-25 function. EMBO J 31:829-841.

Singleton AB, Farrer M, Johnson J, Singleton A, Hague S, Kachergus J, Hulihan M, Peuralinna T, Dutra A, Nussbaum R, Lincoln S, Crawley A, Hanson M, Maraganore D, Adler C, Cookson MR, Muenter M, Baptista M, Miller D, Blancato J, et al. (2003) alpha-Synuclein locus triplication causes Parkinson's disease. Science 302:841.

Spillantini MG, Goedert M (2000) The alpha-synucleinopathies: Parkinson's disease, dementia with Lewy bodies, and multiple system atrophy. Ann N Y Acad Sci 920:16-27.

Sulzer D, Surmeier DJ (2012) Neuronal vulnerability, pathogenesis, and Parkinson's disease. Mov Disord. Advance online publication. Retrieved September 17, 2012.

Tang J, Maximov A, Shin OH, Dai H, Rizo J, Südhof TC (2006) A complexin/synaptotagmin 1 switch controls fast synaptic vesicle exocytosis. Cell 126:1175-1187.

Tofaris GK, Razzaq A, Ghetti B, Lilley KS, Spillantini MG (2003) Ubiquitination of alpha-synuclein in Lewy bodies is a pathological event not associated with impairment of proteasome function. J Biol Chem 278:44405-44411.

Tofaris GK, Garcia Reitböck P, Humby T, Lambourne SL, O'Connell M, Ghetti B, Gossage H, Emson PC, Wilkinson LS, Goedert M, Spillantini MG (2006) Pathological changes in dopaminergic nerve cells of the substantia nigra and olfactory bulb in mice transgenic for truncated human $\alpha$-synuclein(1-120): implications for Lewy body disorders. J Neurosci 26:3942-3950.

Tsika E, Moysidou M, Guo J, Cushman M, Gannon P, Sandaltzopoulos R, Giasson BI, Krainc D, Ischiropoulos H, Mazzulli JR (2010) Distinct region-specific $\alpha$-synuclein oligomers in A53T transgenic mice: implications for neurodegeneration. J Neurosci 30:3409-3418.

Uéda K, Fukushima H, Masliah E, Xia Y, Iwai A, Yoshimoto M, Otero DA, Kondo J, Ihara Y, Saitoh T (1993) Molecular cloning of cDNA encoding an unrecognized component of amyloid in Alzheimer disease. Proc Natl Acad Sci U S A 90:11282-11286.

Ulmer TS, Bax A (2005) Comparison of structure and dynamics of micellebound human alpha-synuclein and Parkinson disease variants. J Biol Chem 280:43179-43187.

Ulmer TS, Bax A, Cole NB, Nussbaum RL (2005) Structure and dynamics of micelle-bound human alpha-synuclein. J Biol Chem 280:9595-9603.

Ulusoy A, Febbraro F, Jensen PH, Kirik D, Romero-Ramos M (2010) Coexpression of C-terminal truncated alpha-synuclein enhances full-length alpha-synuclein-induced pathology. Eur J Neurosci 32:409-422.

Uversky VN, Fink AL (2002) Amino acid determinants of alpha-synuclein aggregation: putting together pieces of the puzzle. FEBS Lett 522:9-13.

Volles MJ, Lansbury PT Jr (2003) Zeroing in on the pathogenic form of alpha-synuclein and its mechanism of neurotoxicity in Parkinson's disease. Biochemistry 42:7871-7878.

Wakamatsu M, Ishii A, Iwata S, Sakagami J, Ukai Y, Ono M, Kanbe D, Muramatsu S, Kobayashi K, Iwatsubo T, Yoshimoto M (2008) Selective loss of nigral dopamine neurons induced by overexpression of truncated human alpha-synuclein in mice. Neurobiol Aging 29:574-585.

Waxman EA, Giasson BI (2008) Specificity and regulation of casein kinasemediated phosphorylation of alpha-synuclein. J Neuropathol Exp Neurol 67:402-416.

Waxman EA, Mazzulli JR, Giasson BI (2009) Characterization of hydrophobic residue requirements for alpha-synuclein fibrillization. Biochemistry 48:9427-9436.

Xu W, Morishita W, Buckmaster PS, Pang ZP, Malenka RC, Südhof TC (2012) Distinct neuronal coding schemes in memory revealed by selective erasure of fast synchronous synaptic transmission. Neuron 73:990-1001.

Yonetani M, Nonaka T, Masuda M, Inukai Y, Oikawa T, Hisanaga S, Hasegawa M (2009) Conversion of wild-type alpha-synuclein into mutanttype fibrils and its propagation in the presence of A30P mutant. J Biol Chem 284:7940-7950.

Zarranz JJ, Alegre J, Gómez-Esteban JC, Lezcano E, Ros R, Ampuero I, Vidal L, Hoenicka J, Rodriguez O, Atarés B, Llorens V, Gomez Tortosa E, del Ser T, Muñoz DG, de Yebenes JG (2004) The new mutation, E46K, of alphasynuclein causes Parkinson and Lewy body dementia. Ann Neurol 55: 164-173. 